\title{
Evidence for positive selection acting on microcystin synthetase adenylation domains in three cyanobacterial genera Ave Tooming-Klunderud ${ }^{1,2}$, David P Fewer ${ }^{3}$, Thomas Rohrlack ${ }^{4,5}$, Jouni Jokela ${ }^{3}$, Leo Rouhiainen ${ }^{3}$, Kaarina Sivonen ${ }^{3}$, Tom Kristensen ${ }^{1,5}$ and Kjetill S Jakobsen*2
}

\author{
Address: ${ }^{1}$ University of Oslo, Department of Molecular Biosciences, 0316 Oslo, Norway, ${ }^{2}$ University of Oslo, Department of Biology, Centre for \\ Ecological and Evolutionary Synthesis (CEES), 0316 Oslo, Norway, ${ }^{3}$ University of Helsinki, Department of Applied Chemistry and Microbiology, \\ P.O. Box 56, Viikki Biocenter, Viikinkaari 9, FIN-00014, Finland, ${ }^{4}$ NIVA, Norwegian Institute for Water Research, 0411 Oslo, Norway and \\ ${ }^{5}$ Department of Biology, Microbial Evolution Research Group (MERG), University of Oslo, 0316 Oslo, Norway \\ Email: Ave Tooming-Klunderud - ave.tooming-klunderud@bio.uio.no; David P Fewer - david.fewer@helsinki.fi; \\ Thomas Rohrlack - thomas.rohrlack@niva.no; Jouni Jokela - jouni.jokela@helsinki.fi; Leo Rouhiainen - leo.rouhiainen@helsinki.fi; \\ Kaarina Sivonen - kaarina.sivonen@ helsinki.fi; Tom Kristensen - tom.kristensen@imbv.uio.no; Kjetill S Jakobsen* - k.s.jakobsen@bio.uio.no \\ * Corresponding author
}

Published: 22 September 2008

BMC Evolutionary Biology 2008, 8:256 doi:10.1 |86/147|-2/48-8-256
Received: 25 March 2008

Accepted: 22 September 2008

This article is available from: http://www.biomedcentral.com/I47I-2I48/8/256

(c) 2008 Tooming-Klunderud et al; licensee BioMed Central Ltd.

This is an Open Access article distributed under the terms of the Creative Commons Attribution License (http://creativecommons.org/licenses/by/2.0), which permits unrestricted use, distribution, and reproduction in any medium, provided the original work is properly cited.

\begin{abstract}
Background: Cyanobacteria produce a wealth of secondary metabolites, including the group of small cyclic heptapeptide hepatotoxins that constitutes the microcystin family. The enzyme complex that directs the biosynthesis of microcystin is encoded in a single large gene cluster (mcy). mcy genes have a widespread distribution among cyanobacteria and are likely to have an ancient origin. The notable diversity within some of the Mcy modules is generated through various recombination events including horizontal gene transfer.

Results: A comparative analysis of the adenylation domains from the first module of McyB (McyBI) and $\mathrm{McyC}$ in the microcystin synthetase complex was performed on a large number of microcystinproducing strains from the Anabaena, Microcystis and Planktothrix genera. We found no decisive evidence for recombination between strains from different genera. However, we detected frequent recombination events in the $m c y B$ and $m c y C$ genes between strains within the same genus. Frequent interdomain recombination events were also observed between mcy $B$ and $m c y C$ sequences in Anabaena and Microcystis. Recombination and mutation rate ratios suggest that the diversification of $m c y B$ and $m c y C$ genes is driven by recombination events as well as point mutations in all three genera. Sequence analysis suggests that generally the adenylation domains of the first domain of $M c y B$ and McyC are under purifying selection. However, we found clear evidence for positive selection acting on a number of amino acid residues within these adenylation domains. These include residues important for active site selectivity of the adenylation domain, strongly suggesting selection for novel microcystin variants.
\end{abstract}

Conclusion: We provide the first clear evidence for positive selection acting on amino acid residues involved directly in the recognition and activation of amino acids incorporated into microcystin, indicating that the microcystin complement of a given strain may influence the ability of a particular strain to interact with its environment. 


\section{Background}

Cyanobacteria produce a wealth of bioactive peptide derivatives with a broad range of biological activities and pharmacological properties [1]. Many of these are synthesized on nonribosomal peptide synthetases (NRPS). These megaenzyme complexes typically have a modular architecture. A typical module contains specific functional domains for activation, thioesterification, and condensation of amino acids [2]. Additional domains for the modification of activated amino acids such as epimerization, heterocyclisation, oxidation, formylation, reduction or $\mathrm{N}$ methylation may also be present [2]. NRPS gene clusters in some cyanobacteria can occupy up to 5 percent of the genome [1].

The modular design of NRPS gene clusters promotes homologous recombination, including recombination within a gene cluster and intragenomic recombination between different gene clusters within the same genome or intergenomic recombination with DNA introduced from other cyanobacteria [3-5]. The cellular consequences of recombination will depend on several factors, including the phenotypic effects, if any, of the introduced DNA segment. In order to be successful, the new gene variant should at least not be detrimental to the host. For NRPS systems, important factors will be whether the novel peptide can fulfil the biological role(s) of the original peptide or provide new benefits to the host. Nonetheless, recombination within and among NRPS gene clusters potentially could constitute a mechanism for continuous alteration of the synthetases and peptide products.

Among cyanobacterial NRPSs, the microcystin synthetase gene clusters $(m c y)$ have been extensively studied. Microcystins are cyclic heptapeptides with common structure cyclo-D-Ala1-X2-D-MeAsp ${ }^{3}-Z^{4}$-Adda ${ }^{5}$-D-Glu ${ }^{6}-\mathrm{Mdha}^{7}$

where D-MeAsp is D-erythro- $\beta$-methyl-aspartic acid, Adda is 3-amino-9-methoxy-2,6,8-trimethyl-10-phenyl-(4E), (6E)-decadienoic acid, D-Glu is D-iso-glutamic acid, and X and $\mathrm{Z}$ are variable $\mathrm{L}$-amino acids (Figure 1 ). Complete gene cluster sequences are available from strains within the Anabaena, Microcystis and Planktothrix genera [6-10]. Recombination in the mcy gene clusters has been reported to involve equivalent modules, i.e. modules with the same position in similar gene clusters [11-13], but also modules in different positions in similar gene clusters or from different gene clusters $[3,14,15]$. Although most strains can produce a range of microcystin isoforms there is a single $m c y$ gene cluster in the genome $[6-8,10,16,17]$, indicating that recombination events involving equivalent domains must be intergenomic.

The substrate specificity of the adenylation (A) domain is considered to be the primary determinant of substrate selection (for a review, see [18]). Recombination events involving A domains might lead to changes in substrate specificity and subsequently in the microcystin profile $[3,15]$. The A domains of modules McyB1 (the first module of the McyB protein) and $\mathrm{McyC}$ recognise and activate the amino acids that are incorporated in the variable positions $\mathrm{X}$ and $\mathrm{Z}$ of microcystin (Figure 1). These A domains have been extensively studied within Microcystis $[13,15]$, and Planktothrix $[11,14]$. Within Microcystis, recombination has lead to the presence of two types of A domains in different strains [15]: a mainly Leu-activating A domain and a mainly Arg-activating A domain that has a high sequence similarity to the Arg-activating A domain in McyC (in the following, these two types of A domains in McyB1 are called B-type and C-like, respectively). Recombination involving A domain coding regions of $m c y B 1$ and $m c y C$ has been detected in Microcystis $[13,15]$ and Anabaena [3,9].

Here, we compare McyB1 and McyC A domains in strains from the three main microcystin-producing genera: Anabaena, Microcystis and Planktothrix to investigate the role of genomic processes in the reshaping of microcystin genes, enzyme complexes and corresponding peptides. We have looked for signs of recombination, both between equivalent and non-equivalent modules, as well as mutations and selective forces acting on these A domains.

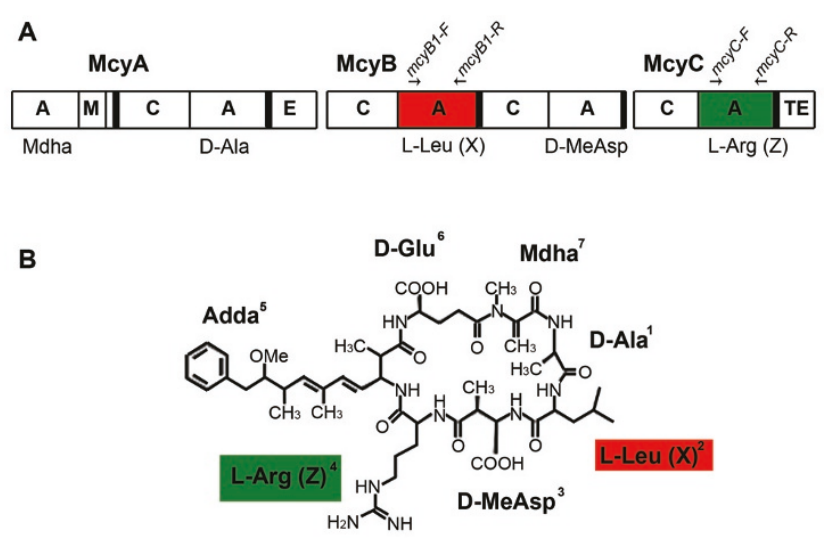

Figure I

Organization of the mcyABC gene cluster (A). Adenylation domains investigated in the present study are indicated in red and green. The relative positions of primers (arrows) are shown. Genus-specific $m c y B$ and $m c y C$ primers are listed in Table 8. (B) The structure of microcystin-LR. Amino acid residues activated by the adenylation domains of $\mathrm{McyBI}$ and $\mathrm{McyC}$ are indicated by red and green, respectively. Mdha is N-methyl-dehydroalanine, D-MeAsp is 3methyl-aspartic acid and Adda is 3-amino-9-methoxy-2,6,8,trimethyl-10-phenyl-4,6-decandienoic acid. 


\section{Results}

In the present study, we have compared A domains of microcystin synthetase modules McyB1 and McyC from altogether 58 strains including 21 Anabaena, 19 Microcystis and 18 Planktothrix strains with characterized microcystinisoform profiles, including two non-producers (Table 1). The profiles made it possible to identify the amino acid residue(s) incorporated by each of these modules.

\section{Microcystin isoforms produced by different genera}

In total, we identified 22 structural variants (Table 1 ), mainly differing in the methylation status of $\mathrm{D}-\mathrm{Asp}^{3}$ or $\mathrm{Dha}^{7}$, but also the amino acid present at position $\mathrm{X}$ (Figure 1). Seven different amino acid residues were found at position X, mainly Leu, Arg and homotyrosine (Hty), but also Phe, homoisoleucine (Hil), homophenylalanine (Hph) and Tyr, while only Arg was found at position $\mathrm{Z}$ (Table 1).

The Anabaena strains mainly produce MC-LR variants, but also several other isoforms, e.g. MC-RR and MC-HtyR (Table 1). Nine Microcystis strains produce MC-RR, either as the only isoform or together with MC-LR and/or MCYR. One strain produces only MC-YR isoforms, while seven strains produce MC-LR isoforms (together with MCYR for two strains) (Table 1). Two of the Microcystis strains examined here have a partial deletion of the $m c y$ gene cluster and do not produce microcystin [13]. Within Planktothrix, 15 of 18 strains produce MC-RR, either as the only isoform ( 5 strains), together with MC-LR ( 8 strains) or together with MC-LR and MC-HtyR (2 strains). The remaining three strains produce mainly MC-HtyR, one of them together with MC-LR (Table 1).

\section{Adenylation domain-encoding sequences of $\mathrm{mcyB} I$ and mcyC}

Analysis of the McyB1 sequences from Anabaena and Planktothrix revealed the presence of a single type of $\mathrm{A}$ domain with a high degree of sequence similarity to the A domain of McyC. Among Microcystis, 7 strains were found to possess a B-type (activating mainly Leu) and 12 strains a C-like (activating mainly Arg - like the McyC) A domain in McyB1 (Table 1, indicated by $\mathrm{B}$ and $\mathrm{C}$, respectively). Phylogenetic analyses of cyanobacterial A domains have shown that the McyB1 sequence from Microcystis strain PCC 7806 (which is of B-type) does not cluster with McyC A domain sequences as do McyB1 sequences from Anabaena and Planktothrix, but clusters with other Leu activating A domains [3,19]. Phylogenetic analysis of 115 McyB1 and $\mathrm{McyC}$ A domain sequences aligned with the remaining Mcy adenylation domains from Microcystis, Anabaena and Planktothrix (acc. nos. AF183408, AJ536156 and AJ441056, respectively) showed also that McyB1 B-type A domains of Microcystis form a clade separate from other McyB1 and McyC sequences (Additional file 1, Figure S1).
Therefore, in the comparisons below of McyB1 sequences from all three genera, only the C-like McyB1 sequences of Microcystis were included.

The variation measured as percentage divergence and nucleotide diversity $(\pi)$ within the $m c y B 1$ sequences was similar in Anabaena $(0-6 \%, \pi=0.032)$ and Microcystis ( 0 $6.3 \%, \pi=0.033)$ and slightly lower $(0-3.6 \%, \pi=0.023)$ in the Planktothrix data set. The sequence variation within $m c y C$ was low in Anabaena $(0-2.4 \%, \pi=0.009)$ and Planktothrix $(0-1.2 \%, \pi=0.003)$ and similar to that of $m c y B 1$ in the Microcystis data set $(0-7.1 \%, \pi=0.035)$ (Table 2). When C-like A domain encoding sequences in $m c y B 1$ were compared with the $m c y C$ sequence from the same strain, genus-specific differences in the genetic variation were observed: $0.7-7.2 \%(\pi=0.037)$ in Anabaena strains, $8.6-$ $12.4 \%(\pi=0.035)$ in Microcystis strains and $29.8-30.8 \%$ $(\pi=0.158)$ in Planktothrix strains (Table 2). Interestingly, the sequences from the non-producing Microcystis strains did not diverged from the rest, suggesting insufficient time for any divergence or that the selective constraints still are the same.

\section{Variation in evolutionary rates between genera and between McyBI and McyC}

Phylogenetic analyses of the amino acid sequence alignment of the 108 McyB1 and McyC A domain sequences yielded a similar tree topology for all methods used $(\mathrm{ML}$, Bayesian and NJ, Figure 2). Five well-supported main clades were observed: McyB1/McyC of Anabaena, McyB1 of Microcystis, McyC of Microcystis, McyB1 of Planktothrix and McyC of Planktothrix. All clades were genus-specific. The McyB1 and McyC sequences from Microcystis formed two separate clades, as did the McyB1 and McyC sequences from Planktothrix, but the A domains of Planktothrix were separated on longer branches. Interestingly, within the Anabaena clade, no distinct, well-supported McyC clade was inferred. Almost all Anabaena McyB1 sequences formed a clade with moderate support (PP 0.98 , BS-ML 69\%, BS-NJ 83\%), except for the sequences from strains 288, N-C 267/4 and 18B6. The McyB1 sequence from strain $18 \mathrm{~B} 6$ clustered with the $\mathrm{McyC}$ sequence from the same strain with moderate support (PP 0.93, BS-ML 65\%, BS-NJ 84\%).

\section{Mutation rates and recombination within- and between McyBI and McyC adenylation domains}

The mutation rates ranged from 0.0076 to 0.0359 , being lowest in $m c y C$ of Anabaena and Planktothrix (Table 3). Moderate recombination levels $(0.010 \leq \rho \leq 0.027$ per base) (Table 3) were detected in all data sets except for $m c y C$ from Planktothrix. Low recombination levels were estimated for this data set, but all three permutation tests indicated that recombination rate was not statistically significant different from 0 . Recombination rate/mutation 
Table I: Strains compared in present study

\begin{tabular}{|c|c|c|c|c|c|}
\hline \multirow[t]{2}{*}{ Strain\# } & \multirow[t]{2}{*}{ Geographic origin } & \multirow[t]{2}{*}{ Year } & \multirow{2}{*}{$\begin{array}{c}\text { Genes }^{\&} \\
\begin{array}{c}\text { mcyB* } \\
\text { mcyC }\end{array}\end{array}$} & \multirow[t]{2}{*}{ Microcystin isoforms produced [reference] } & \\
\hline & & & & & \\
\hline \multicolumn{6}{|l|}{ Anabaena } \\
\hline $\mathrm{N}-\mathrm{C} 83 / \mathrm{l}$ & L. Edlandsvatnet, Norway & 1981 & $\begin{array}{l}\text { EU009900 } \\
\text { EU009918 }\end{array}$ & [D-Asp3]MC-LR, [D-Asp ] $3 C-R R, M C-L R, M C-R R$ & {$[56]$} \\
\hline N-C 267/4 & L. Fammestadtjønni, Norway & 1990 & $\begin{array}{l}\text { EU009901 } \\
\text { EU009919 }\end{array}$ & $\begin{array}{l}\text { MC-HtyR, MC-LR, MC-FR, [D-Asp }{ }^{3} \text { MC-LR, [D- } \\
\left.\text { Asp }^{3}\right] \text { MC-HtyR, [D-Asp } 3 \text { MC-FR, MC-HilR, MC-HphR }\end{array}$ & [56] \\
\hline $\mathrm{N}-\mathrm{C} 269 / 2$ & L. Frøylandsvatnet, Norway & 1990 & $\begin{array}{l}\text { EU009902 } \\
\text { EU009920 }\end{array}$ & $\begin{array}{l}\left.\text { [D-Asp }{ }^{3}\right] M C-L R, M C-H t y R,\left[D-A s p^{3}\right] M C-H t y R, M C-L R, \\
{\left[D-A s p^{3}\right] M C-F R, M C-F R, M C-H i l R, M C-H p h R,[D-} \\
\left.\text { Asp }^{3}\right] M C-H i l R,\left[D-A s p^{3}\right] M C-H p h R\end{array}$ & [56] \\
\hline N-C $269 / 6$ & L. Frøylandsvatnet, Norway & 1990 & $\begin{array}{l}E U 009903 \\
\text { EU009921 }\end{array}$ & $\begin{array}{l}\left.\text { [D-Asp }{ }^{3}\right] M C-L R, M C-H t y R,\left[D-A s p^{3}\right] M C-H t y R, M C-L R \\
{\left[D-A s p^{3}\right] M C-F R, M C-F R, M C-H i l R, M C-H p h R,[D-} \\
\left.\text { Asp }^{3}\right] M C-H i l R,\left[D-A s p^{3}\right] M C-H p h R\end{array}$ & [56] \\
\hline N-C 270/I & L. Arefjordsvatnet, Norway & 1990 & $\begin{array}{l}\text { EU009904 } \\
\text { EU009933 }\end{array}$ & [D-Asp3]MC-LR, MC-LR, [D-Asp3]MC-RR, MC-RR & [56] \\
\hline 90 & L. Vesijärvi, Finland & 1986 & $\begin{array}{l}\text { AJ536156 } \\
\text { AJ536156 }\end{array}$ & $\begin{array}{l}\text { MC-LR, [D-Asp } 3 \text { MC-LR, MC-RR, [D-Asp3]MC-RR, MC- } \\
\text { HilR, [D-Asp3]MC-HilR }\end{array}$ & [9] \\
\hline ITU44SI6 & L. Tuusulanjärvi, Finland & 2001 & $\begin{array}{l}\text { EU009887 } \\
\text { EU009905 }\end{array}$ & {$\left[D-A s p^{3}\right] M C-L R, M C-L R$} & {$[56]$} \\
\hline ITU30S4 & L. Tuusulanjärvi, Finland & 2001 & $\begin{array}{l}\text { EU009888 } \\
\text { EU009906 }\end{array}$ & {$\left[\mathrm{Dha}^{7}\right] \mathrm{MC}-\mathrm{LR},\left[\mathrm{D}-\mathrm{Asp}^{3}, \mathrm{Dha}^{7}\right] \mathrm{MC}-\mathrm{LR},\left[\mathrm{L}-\mathrm{Ser}^{7}\right] \mathrm{MC}-\mathrm{LR}$} & [56] \\
\hline ITU3IS9 & L. Tuusulanjärvi, Finland & 2001 & $\begin{array}{l}\text { EU009889 } \\
\text { EU009907 }\end{array}$ & $\begin{array}{l}{\left[\mathrm{Dha}^{7}\right] M C-L R,\left[D-A s p^{3}, \mathrm{Dha}^{7}\right] M C-L R,\left[L-\text { Ser }^{7}\right] M C-L R,} \\
{\left[D-A s p^{3} \text {, demet-N }{ }^{7}\right] M C}\end{array}$ & {$[56]$} \\
\hline $202 \mathrm{Al} / 35$ & L. Vesijärvi, Finland & 1987 & $\begin{array}{l}\text { EU009890 } \\
\text { EU009908 }\end{array}$ & {$\left[\mathrm{D}-\mathrm{Asp}^{3}, \mathrm{Dha}^{7}\right] \mathrm{MC}-\mathrm{LR},\left[\mathrm{Dha}^{7}\right] \mathrm{MC}-\mathrm{LR},\left[\mathrm{L}-\mathrm{Ser}^{7}\right] \mathrm{MC}-\mathrm{LR}$} & {$[56]$} \\
\hline ITU46SII & L. Tuusulanjärvi, Finland & 2001 & $\begin{array}{l}\text { EU009891 } \\
\text { EU009909 }\end{array}$ & {$\left[D-A s p^{3}\right] M C-L R, M C-L R,\left[D-A s p^{3}\right] M C-H i l R$} & {$[56]$} \\
\hline $202 A 2 / 41$ & L. Vesijärvi, Finland & 1987 & $\begin{array}{l}\text { EU009892 } \\
\text { EU009910 }\end{array}$ & $\begin{array}{l}{\left[\mathrm{D}-\mathrm{Asp}^{3}, \mathrm{Dha}^{7}\right] \mathrm{MC}-\mathrm{LR},\left[\mathrm{Dha}^{7}\right] \mathrm{MC}-\mathrm{LR},\left[\mathrm{L}-\mathrm{Ser}^{7}\right] \mathrm{MC}-\mathrm{LR},} \\
{\left[\mathrm{D}-\mathrm{Asp}^{3}, \text { demet-N7}\right] \mathrm{MC}}\end{array}$ & {$[56]$} \\
\hline 0TU33SI6 & L. Tuusulanjärvi, Finland & 2000 & $\begin{array}{l}\text { EU009893 } \\
\text { EU00991I }\end{array}$ & {$\left[\mathrm{D}-\mathrm{Asp} \mathrm{P}^{3}\right] \mathrm{MC}-\mathrm{LR}, \mathrm{MC}-\mathrm{LR},\left[\mathrm{D}-\mathrm{Asp} \mathrm{P}^{3}\right] \mathrm{MC}-\mathrm{HilR}$} & {$[56]$} \\
\hline 258 & L. Tuusulanjärvi, Finland & 1990 & $\begin{array}{l}\text { EU009894 } \\
\text { EU009912 }\end{array}$ & MC-LR, [D-Asp³]MC-LR, MC-HilR, [D-Asp3]MC-HilR & {$[56]$} \\
\hline ITU32SII & L. Tuusulanjärvi, Finland & 2001 & $\begin{array}{l}\text { EU009895 } \\
\text { EU009913 }\end{array}$ & {$\left[\mathrm{Dha}^{7}\right] \mathrm{MC}-\mathrm{LR},\left[\mathrm{D}-\mathrm{Asp}^{3}, \mathrm{Dha}^{7}\right] \mathrm{MC}-\mathrm{LR},\left[\mathrm{L}-\mathrm{Ser}^{7}\right] \mathrm{MC}-\mathrm{LR}$} & {$[56]$} \\
\hline BIR 246 & Gulf of Finland, Baltic Sea & 2004 & $\begin{array}{l}\text { EU009896 } \\
\text { EU009914 }\end{array}$ & $\begin{array}{l}\left.\text { [D-Asp33]MC-HtyR, MC-HtyR, [D-Asp }{ }^{3}\right] M C-L R, M C-L R, \\
\left.\text { [D-Asp }{ }^{3}\right] M C-F R, M C-F R, M C-H p h R,\left[D-A s p^{3}\right] M C- \\
\text { HphR, MC-HilR, D-Asp } 3 \text { MC-HilR }\end{array}$ & {$[56]$} \\
\hline 288 & Littoisten vesilaitos, Finland & 1990 & $\begin{array}{l}\text { EU009897 } \\
\text { EU009915 }\end{array}$ & $\begin{array}{l}\text { MC-HtyR, MC-LR, MC-FR, [D-Asp3]MC-LR, [D- } \\
\text { Asp } 3 \text { MC-HtyR, MC-HphR, [D-Asp } 3 \text { MC-FR, }\end{array}$ & {$[56]$} \\
\hline 315 & Gulf of Finland, Baltic Sea & 1997 & $\begin{array}{l}\text { EU009898 } \\
\text { EU009916 }\end{array}$ & $\begin{array}{l}{\left[\text { Dha }{ }^{7}\right] M C-H t y R,\left[D-A s p^{3}, \text { Dha }^{7}\right] M C-H t y R,\left[D h a^{7}\right] M C-} \\
\text { LR }\end{array}$ & {$[56]$} \\
\hline 318 & Gulf of Finland, Baltic Sea & 1998 & $\begin{array}{l}\text { EU009899 } \\
\text { EU009917 }\end{array}$ & MC-HtyR, [D-Asp $\left.{ }^{3}\right] M C-H t y,\left[D-A s p^{3}\right] M C-L R, ~ M C-L R$ & {$[56]$} \\
\hline $66 \mathrm{~A}$ & L. Sääskjärvi, Finland & 1986 & $\begin{array}{l}\text { EUI51874 } \\
\text { EUI51867 }\end{array}$ & 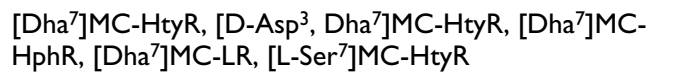 & {$[56]$} \\
\hline I8B & L. Vaaranlampi, Finland & 1986 & $\begin{array}{l}\text { EUI5I873 } \\
\text { EUI5I866 }\end{array}$ & {$\left[\mathrm{D}-\mathrm{Asp}^{3} \mathrm{Dha}^{7}\right] \mathrm{MC}-\mathrm{RR},\left[\mathrm{Dha}^{7}\right] \mathrm{MC}-\mathrm{RR}$} & [56] \\
\hline \multicolumn{6}{|l|}{ Microcystis } \\
\hline $\mathrm{N}-\mathrm{C} 31$ & Little Rideau Lake, Canada & 1954 & $\begin{array}{c}\text { EU009866 B } \\
\text { EFII5396 }\end{array}$ & MC-LR & {$[15]$} \\
\hline N-C 57 & L. Frøylandsvatnet, Norway & 1978 & $\begin{array}{l}\text { EU009867 C } \\
\text { EFII } 5397\end{array}$ & {$\left[\mathrm{Asp}^{3}, \mathrm{Dha}^{7}\right] \mathrm{MC}-\mathrm{RR},\left[\mathrm{Dha} \mathrm{F}^{7}\right] \mathrm{MC}-\mathrm{RR}$} & {$[15]$} \\
\hline $\mathrm{N}-\mathrm{C} \perp 18 / 2$ & L. Gjersjøen, Norway & 1983 & $\begin{array}{l}\text { EU009868 B } \\
\text { EFII } 5398\end{array}$ & {$\left[\mathrm{Asp}^{3}\right] \mathrm{MC}-\mathrm{LR}, \mathrm{MC}-\mathrm{LR}$} & {$[15]$} \\
\hline $\mathrm{N}-\mathrm{C} 140$ & Bendig's Pond, Canada & 1975 & $\begin{array}{l}\text { EU009869 B } \\
\text { EU00988I }\end{array}$ & MC-LR, MC-desmethyl-LR & This work \\
\hline $\mathrm{N}-\mathrm{C} 143$ & L. Akersvatnet, Norway & 1984 & $\begin{array}{l}\text { EU009870 C } \\
\text { EFII } 5399\end{array}$ & None & {$[15]$} \\
\hline $\mathrm{N}-\mathrm{C} 160 / 2$ & L. Akersvatnet, Norway & 1985 & $\begin{array}{l}\text { EU00987I C } \\
\text { EU009882 }\end{array}$ & None & This work \\
\hline $\mathrm{N}-\mathrm{C} 161 / 1$ & L. Mosvatnet, Norway & 1985 & $\begin{array}{l}\text { EU009872 B } \\
\text { EFII } 5400\end{array}$ & MC-YR, MC-LR & {$[15]$} \\
\hline
\end{tabular}


Table I: Strains compared in present study (Continued)

\begin{tabular}{|c|c|c|c|c|c|}
\hline $\mathrm{N}-\mathrm{C}$ 169/7 & L. Arresø, Denmark & 1985 & $\begin{array}{c}\text { EU009873 C } \\
\text { EFII540I }\end{array}$ & MC-RR, MC-LR & [15] \\
\hline $\mathrm{N}-\mathrm{C} 171 / 10$ & L. Arresø, Denmark & 1985 & $\begin{array}{l}\text { EU009874 C } \\
\text { EU009883 }\end{array}$ & MC-LR, MC-YR, MC-RR & This work \\
\hline N-C 228/I & L. Akersvatnet, Norway & 1985 & $\begin{array}{l}\text { EU009875 C } \\
\text { EFII } 5402\end{array}$ & {$\left[\mathrm{Dha}^{7}\right] \mathrm{MC}-\mathrm{RR},\left[\mathrm{Dha}^{7}\right] \mathrm{MC}-\mathrm{LR}$} & {$[15]$} \\
\hline N-C 264 & L. Frøylandsvatnet, Norway & 1990 & $\begin{array}{l}\text { EU009876 C } \\
\text { EFII } 5403\end{array}$ & {$\left[\mathrm{Dha}^{7}\right] \mathrm{MC}-\mathrm{RR}$} & {$[15]$} \\
\hline N-C 324/I & L. Tøråssjøen, Norway & 1993 & $\begin{array}{l}\text { EU009877 C } \\
\text { EFII } 5404\end{array}$ & $\begin{array}{l}{\left[\text { Asp }^{3}, \mathrm{Dha}^{7}\right] \mathrm{MC}-\mathrm{RR},\left[\mathrm{Dha}^{7}\right] \mathrm{MC}-\mathrm{RR},\left[\mathrm{Dha}^{7}\right] \mathrm{MC}-\mathrm{LR}, \mathrm{MC}-} \\
\mathrm{LR}\end{array}$ & {$[15]$} \\
\hline N-C 357 & River Zala, Hungary & 1996 & $\begin{array}{l}\text { EU009878 C } \\
\text { EU009884 }\end{array}$ & MC-RR, MC-LR, MC-YR, MC-desmethyl-LR & This work \\
\hline N-C 496 & Queen Elizabeth Channel, Uganda & 2004 & $\begin{array}{l}\text { EU009879 C } \\
\text { EU009885 }\end{array}$ & MC-YR, MC-desmethyl-YR & This work \\
\hline AB2002/24 & Pilsner Pond, Kenya & 2002 & $\begin{array}{l}\text { EU009880 B } \\
\text { EU009886 }\end{array}$ & MC-LR, desmethyl-MC-YR, MC-YR & [57] \\
\hline UV027 & Germany & ND & $\begin{array}{l}\text { AF458094 C } \\
\text { AF458094 }\end{array}$ & MC-RR & [9] \\
\hline PCC 7806 & Braakman Reservoir, The Netherlands & 1972 & $\begin{array}{l}\text { AFI } 83408 \text { B } \\
\text { AFI83408 }\end{array}$ & MC-LR, $\left[\right.$ Asp $\left.{ }^{3}\right] M C-L R$ & {$[10]$} \\
\hline $\mathrm{K}-139$ & Lake Kasumigaura, Japan & 1985 & $\begin{array}{l}A B 019578 B \\
A B 019578\end{array}$ & {$\left[\mathrm{Dha}^{7}\right] \mathrm{MC}-\mathrm{LR},\left[\mathrm{Asp}^{3}, \mathrm{Dha}^{7}\right] \mathrm{MC}-\mathrm{LR}$} & [58] \\
\hline NIES 102 & Lake Kasumigaura, Japan & 1982 & AB092807 C & MC-LR, MC-RR, MC-YR & [58] \\
\hline \multicolumn{6}{|l|}{ Planktothrix } \\
\hline 3 & L. Mondsee, Austria & 2001 & $\begin{array}{l}\text { A)749276 } \\
\text { AJ749285 }\end{array}$ & {$\left[\right.$ Asp $^{3}$, Mdha $\left.^{7}\right] M C-R R$} & [14] \\
\hline 64 & L. Wörthersee, Austria & 2001 & $\begin{array}{l}\text { AJ749277 } \\
\text { AJ749286 }\end{array}$ & {$\left[\right.$ Asp $^{3}$, Mdha $\left.^{7}\right] M C-R R$} & [14] \\
\hline 111 & L. Mondsee, Austria & 2001 & $\begin{array}{l}\text { Aj749282 } \\
\text { AJ749291 }\end{array}$ & {$\left[\right.$ Asp $^{3}$, Mdha $\left.^{7}\right] M C-R R$} & [14] \\
\hline $31 / 1$ & L. Wannsee, Germany & 2001 & $\begin{array}{l}\text { AJ749267 } \\
\text { AJ749294 }\end{array}$ & {$\left[\right.$ Asp $^{3}$, Mdha $\left.{ }^{7}\right] M C-R R,\left[\right.$ Asp $\left.^{3}\right] M C-H t y R,\left[\right.$ Asp $\left.^{3}\right] M C-L R$} & [14] \\
\hline 32 & L. Wannsee, Germany & 2001 & $\begin{array}{l}\text { AJ749268 } \\
\text { AJ749295 }\end{array}$ & {$\left[\right.$ Asp $^{3}$, Mdha $\left.^{7}\right] M C-R R,\left[\right.$ Asp $\left.^{3}\right] M C-L R$} & [14] \\
\hline 39 & L. Wannsee, Germany & 2001 & $\begin{array}{l}\text { AJ749269 } \\
\text { AJ749296 }\end{array}$ & {$\left[\right.$ Asp $^{3}$, Mdha $\left.^{7}\right] M C-R R,\left[\right.$ Asp $\left.^{3}\right] M C-L R$} & [14] \\
\hline 79 & L. Arresø, Denmark & 2001 & $\begin{array}{l}\text { Aj749270 } \\
\text { AJ749297 }\end{array}$ & {$\left[\right.$ Asp $^{3}$, Mdha $\left.^{7}\right] M C-R R,\left[\right.$ Asp $\left.^{3}\right] M C-L R$} & [14] \\
\hline SAG 6.89 & L. Plußsee, Plön, Germany & 1969 & $\begin{array}{l}\text { AJ74927I } \\
\text { AJ749298 }\end{array}$ & {$\left[\right.$ Asp $\left.^{3}, \mathrm{Mdha}^{7}\right] \mathrm{MC}-\mathrm{RR},\left[\mathrm{Asp}^{3}\right] \mathrm{MC}-\mathrm{LR}$} & [14] \\
\hline $\mathrm{N}-\mathrm{C} 126 / 8$ & L. Langsjön Finland & 1984 & $\begin{array}{l}\text { Aj} 441056 \\
\text { AJ } 441056\end{array}$ & {$\left[\right.$ Asp $^{3}$, Mdha $\left.^{7}\right] M C-R R,\left[\right.$ Asp $\left.^{3}\right] M C-L R$} & [6] \\
\hline 80 & L. Schwarzensee, Austria & 2001 & $\begin{array}{l}\text { Aj749278 } \\
\text { AJ749287 }\end{array}$ & MC-HtyR & [II] \\
\hline 82 & L. Ammersee, Germany & 2001 & $\begin{array}{l}\text { Aj749279 } \\
\text { AJ749288 }\end{array}$ & {$\left[\mathrm{Asp}^{3}, \mathrm{Dhb}^{7}\right] \mathrm{MC}-\mathrm{RR},\left[\mathrm{Asp}^{3}\right] \mathrm{MC}-\mathrm{HtyR},\left[\mathrm{Asp}^{3}\right] \mathrm{MC}-\mathrm{LR}$} & [14] \\
\hline 108 & L. Irrsee, Austria & 2001 & $\begin{array}{l}\text { Aj74928I } \\
\text { AJ749290 }\end{array}$ & {$\left[\mathrm{Asp}^{3}, \mathrm{Dhb}^{7}\right] \mathrm{MC}-\mathrm{RR},\left[\mathrm{Asp}^{3}\right] \mathrm{MC}-\mathrm{LR}$} & [14] \\
\hline PCC 782I & L. Gjersjøen, Norway & 1971 & $\begin{array}{l}\text { Aj749283 } \\
\text { AJ749292 }\end{array}$ & {$\left[\mathrm{Asp}^{3}, \mathrm{Dhb}^{7}\right] \mathrm{MC}-\mathrm{RR},\left[\mathrm{Asp}^{3}\right] \mathrm{MC}-\mathrm{LR}$} & [14] \\
\hline $\begin{array}{l}\text { CCAP } \\
1459 / 30\end{array}$ & L. Plöner See, Germany & ND & $\begin{array}{l}\text { Aj749284 } \\
\text { AJ749293 }\end{array}$ & {$\left[\mathrm{Asp}^{3}, \mathrm{Dhb}^{7}\right] \mathrm{MC}-\mathrm{RR},\left[\mathrm{Asp}^{3}\right] \mathrm{MC}-\mathrm{LR}$} & {$[14]$} \\
\hline $\begin{array}{l}\text { CCAP } \\
\text { I459/I IA }\end{array}$ & L. Windermere, UK & 1975 & $\begin{array}{l}\text { AJ749272 } \\
\text { AJ749299 }\end{array}$ & {$\left[\mathrm{Asp}^{3}, \mathrm{Dhb}^{7}\right] \mathrm{MC}-\mathrm{RR}$} & [14] \\
\hline $\begin{array}{l}\text { CCAP } \\
|459 / 2|\end{array}$ & Esthwaite Water, UK & 1985 & $\begin{array}{l}\text { Aj7499274 } \\
\text { AJ74930 I }\end{array}$ & {$\left[\mathrm{Asp}^{3}, \mathrm{Dhb}^{7}\right] \mathrm{MC}-\mathrm{RR}$} & [14] \\
\hline $\begin{array}{l}\text { CCAP } \\
1460 / 5\end{array}$ & L. Kasumigaura, Japan & 1983 & $\begin{array}{l}\text { Aj749275 } \\
\text { AJ749302 }\end{array}$ & {$\left[\right.$ Asp $\left.^{3}\right] M C-H t y R,\left[\right.$ Asp $\left.^{3}\right] M C-L R$} & [14] \\
\hline $\begin{array}{l}\text { CCAP } \\
1459 / 16\end{array}$ & Blelham Tarn, UK & 1979 & $\begin{array}{l}\text { Aj749273 } \\
\text { AJ749300 }\end{array}$ & {$\left[\right.$ Asp $\left.^{3}\right] M C-H t y R,\left[\right.$ Asp $\left.^{3}\right] M C-L R$} & [14] \\
\hline
\end{tabular}

\# N-C, NIVA-CYA, Norwegian Institute for Water Research Cyanobacterial Culture Collection, PCC, Pasteur Culture Collection, NIES, National Institute for Environmental Studies Microbial Culture Collection, Japan, CCAP Culture Collection of Algae and Protozoa (Windermere, UK).

\&GenBank accession numbers for the microcystin synthetase genes analyzed. For each strain, the upper acc. no. indicates mcyB sequence.

* For Microcystis strains, the type of McyB A domain, B-type or C-like is indicated by $B$ and $C$, respectively.

ND - no data available 
Table 2: Genetic information

\begin{tabular}{|c|c|c|c|c|c|c|c|c|}
\hline \multirow[t]{2}{*}{ Genus } & \multirow[t]{2}{*}{ No of seq } & \multirow{2}{*}{$\begin{array}{l}\text { Length } \\
\text { (bp) }\end{array}$} & \multirow[t]{2}{*}{$\pi$} & \multirow{2}{*}{$\begin{array}{l}\text { Sequence } \\
\text { variation }\end{array}$} & \multirow{2}{*}{$\begin{array}{c}\text { No of segregating } \\
\text { sites/informative } \\
\text { sites }\end{array}$} & \multicolumn{3}{|c|}{ Putative recombination events } \\
\hline & & & & & & $\begin{array}{c}\text { Mosaic structure } \\
\text { of informative } \\
\text { sites }\end{array}$ & $\begin{array}{l}\text { Detected by } \\
\text { programs of } \\
\text { RDP2 package }\end{array}$ & $\begin{array}{l}\text { Detected by } \\
\text { SplitsTree } \\
\text { (Phi test for } \\
\text { recomb) }\end{array}$ \\
\hline \multicolumn{9}{|c|}{ Anabaena } \\
\hline$m c y B$ & 21 & 1068 & 0.032 & $0-6 \%$ & $100 / 79$ & $Y$ & $\mathrm{Y}$ & $Y,(P<0.01)$ \\
\hline mcyC & 21 & 1068 & 0.009 & $0-2.4 \%$ & $31 / 28$ & Y & $\mathrm{N}$ & $Y,(P<0.01)$ \\
\hline$m c y B C$ & 42 & 1068 & 0.036 & $0.7-7.2 \% *$ & $107 / 94$ & Y & $\mathrm{Y}$ & $Y,(P<0.01)$ \\
\hline \multicolumn{9}{|c|}{ Microcystis } \\
\hline$m c y B$ & 12 & $1059 / 1062$ & 0.033 & $0-6.3 \%$ & $111 / 57$ & Y & Y & $Y,(P<0.01)$ \\
\hline mcyC & 18 & $1059 / 1062$ & 0.035 & $0-7.1 \%$ & $131 / 99$ & Y & Y & $Y,(P<0.01)$ \\
\hline mсуBC & 30 & $1059 / 1062$ & 0.073 & $8.6-12.4 \% *$ & $222 / 192$ & Y & Y & $\mathrm{Y},(P<0.0 \mathrm{I})$ \\
\hline \multicolumn{9}{|c|}{ Planktothrix } \\
\hline mсуB & 18 & 1080 & 0.023 & $0-3.6 \%$ & $61 / 61$ & Y & Y & $Y,(P<0.01)$ \\
\hline mcyC & 18 & 1068 & 0.003 & $0-1.2 \%$ & $27 / 0$ & $\mathrm{~N}$ & $\mathrm{~N}$ & $\mathrm{~N}$ \\
\hline mсуBC & 36 & $1068 / 1080$ & 0.158 & $29.8-30.8 \% *$ & $354 / 353$ & $\mathrm{~N}$ & $\mathrm{~N}$ & $\mathrm{Y},(P<0.01)^{\&}$ \\
\hline \multicolumn{9}{|c|}{ Comparison of adenylation domains between genera } \\
\hline$m c y B i$ & 51 & $1062-1080$ & 0.206 & $27-34 \% \#$ & $487 / 487$ & $\mathrm{~N} \ddagger$ & $\mathrm{N} \ddagger$ & $\mathrm{N} \ddagger$ \\
\hline mcyc & 57 & 1068 & 0.161 & $18-29 \% \S$ & $4 I I / 4 I I$ & $\mathrm{~N} \ddagger$ & $\mathrm{N} \ddagger$ & $\mathrm{N} \ddagger$ \\
\hline
\end{tabular}

$\pi$ Nucleotide diversity - the average number of nucleotide differences per site between two sequences

* Sequence variation between $m c y B I$ and $m c y C$ sequences

\# Sequence variation is $27-30 \%$ between Anabaena and Microcystis, 30-32\% between Anabaena and Planktothrix, 32-34\% between Microcystis and Planktothrix.

\$ Sequence variation is 26-29\% between Anabaena and Microcystis, 18-19\% between Anabaena and Planktothrix, 23-26\% between Microcystis and Planktothrix.

$\ddagger$ Recombination detection between genera

\& Recombination detected within $m c y B I$

rate ratios below 1 in the Microcystis and Planktothrix data sets (Table 3) suggest that point mutations are the main cause of genetic variation in McyB1 and McyC A domains from these genera. In contrast, a recombination rate/ mutation rate ratio higher than 1 in the Anabaena data sets indicates that recombination has had a major impact on these A domains.

Recombination events were also suggested in all data sets by the mosaic structure of informative sites, with the exception of $m c y C$ from Planktothrix (Figure 3). The reticulate phylogenies revealed by the split decomposition analysis (Figures 4 and 5) were supported by Phi test (Table 2) in all data sets except mcyC from Planktothrix. Recombination detection programs (RDP, GENECONV and MaxChi) identified several recombination breakpoints along the entire $m c y B 1$ sequences in Anabaena and Planktothrix strains, while only one single putative recombination event was detected within the Microcystis mcyB1 and $m c y C$ data sets (Table 4). No recombination events were suggested by recombination detection programs within the mcyC alignments of Anabaena and Planktothrix. The analyses of the combined $m c y B 1 C$ data sets (Figure 6 , Table 5) suggested recombination events between mcyB1 and $m c y C$ in Anabaena and Microcystis, but not in Planktothrix.

\section{Substrate specificity of MycB I and McyC adenylation domains}

McyB1 and McyC A domain sequences were aligned with the Phe-activating A domain of GrsA [20] to identify the binding-pocket residues. The binding pocket signatures of McyC A domains (activating mainly Arg) were more or less identical within the genus, while only five residues are identical in binding pocket signatures from all three genera (Table 6). Binding pocket signatures are more diverse in McyB1 A domains, reflecting the diversity of amino acid residues incorporated in position $\mathrm{X}$ (Table 6). Some McyB1 modules with identical binding pocket signatures incorporate a somewhat different set of amino acid residues (e.g. Microcystis strains N-C 357 and N-C 496, Table $6)$, indicating that other residues in the A domain or other 


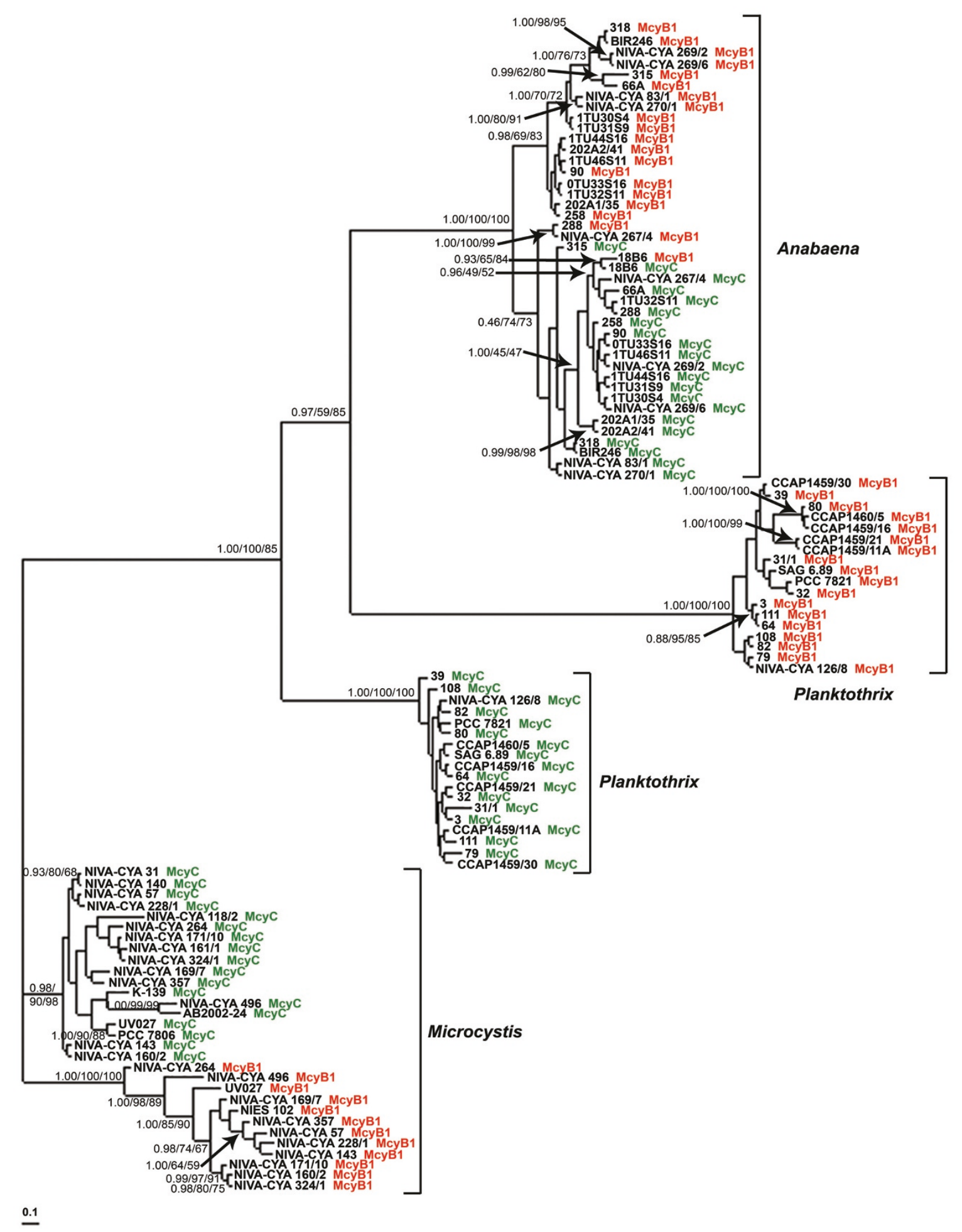

Figure 2

(A) Phylogenetic analysis of adenylation domains of McyB I and McyC. The Bayesian tree is shown with support from maximum likelihood tree ( 1000 replicates and neighbor-joining tree (1000 replicates). Bayesian posterior probability/ML bootstrap/NJ bootstrap values are shown. Only bootstrap values above $50 \%$ are shown. Adenylation domains of McyBI and McyC from all genera are indicated by red and green, respectively. 
Table 3: Recombination and mutation rates

\begin{tabular}{lllll}
\hline Genus & Region analyzed & $\rho^{\mathbf{a}}$ & $\Theta_{\mathbf{w}^{\mathbf{a}}}$ & $\rho / \Theta_{\mathbf{W}}$ \\
\hline Anabaena & $m c y B I$ & $0.0234^{* *}$ & 0.0206 & 1.136 \\
Anabaena & $m c y C$ & $0.0178^{*}$ & 0.0086 & 2.070 \\
Microcystis & $m c y B I$ & $0.0226^{* *}$ & 0.0346 & 0.653 \\
Microcystis & $m c y C$ & $0.0273^{* *}$ & 0.0359 & 0.760 \\
Planktothrix & $m c y B I$ & $0.0102^{* *}$ & 0.0164 & 0.622 \\
Planktothrix & $m c y C$ & $0.0019^{\#}$ & 0.0076 & $0 \#$ \\
\hline
\end{tabular}

a recombination rate $(\rho)$ and mutation rate $\left(\Theta_{W}\right)$ per base

$* P<0.05$ for at least two of three permutation tests implemented in LDhat package

** $P<0.001$ for at least two of three permutation tests implemented in LDhat package

\# All three permutation tests suggested that recombination rate is not significantly different form 0 .

domains, such as the condensation domain influence substrate specificity. A role of the condensation domain in substrate selection has been suggested by several studies (for a review, see [18]).

\section{Adenylation domains and selective forces}

An excess of synonymous over non-synonymous substitutions $(\omega<1)$ (Table 7$)$ was observed in all data sets, indicating that the A domains of McyB1 and McyC overall are under purifying selection in all three genera. Small fractions $(0.3-10.4 \%)$ of codons under positive selection were detected in all data sets except for McyC from Planktothrix (Table 7). The number of potential sites under positive selection with statistical support $(\mathrm{P}>90 \%)$ ranged from 3 to 8 (Table 7) and their positions in the A domain alignment are shown in Figure 7. Interestingly, in both Anabaena data sets as well as in the Planktothrix McyB1 data set, the binding pocket residue 278 (Figure 7, Table 7) appears to be under positive selection. In the Microcystis McyC data set, this is also the case for the amino acid residue between binding pocket residues 299 and 301 (Figure 7). Among residues not present in binding pocket signatures, site 205 in the McyC alignments in both Microcystis and Anabaena and site 350 in both Microcystis data sets (Figure 7) were suggested to be under positive selection.

Branch-site models were used to detect possible positive selection acting on the McyB1 sequences from Anabaena and Planktothrix strains that incorporate Hty in position X. (Table 1, Figure 2). There were no statistically significant differences between the log-likelihood values of the alternative models and the null models (data not shown), indicating no evidence for positive selection in domains incorporating Hty.

\section{Discussion}

This study is so far the most extensive comparative analysis of microcystin synthetase adenylation domains for the modules McyB1 and McyC. The phylogenetic trees of the 108 adenylation domain sequences showed clustering according to module and genus (Figure 2). Our data set revealed no signs of recombination between genera, in agreement with previous studies on $m c y$ genes $[3,21]$ and similar studies from other NRPS gene clusters $[19,22]$. This also is in line with other studies that show that the rate of successful homologous recombination rapidly is reduced with increased genetic distance [23-25].

\section{The evolutionary history of the McyB I A domain}

It is not clear at present which of the two types of $A$ domains in McyB1, was present in the ancestral microcystin synthetase. A B-type ancestral A domain implies that after segregation of the genera, some Microcystis strains and all Anabaena and Planktothrix acquired a C-like type of A domain in McyB1, most likely through intragenomic recombination between $m c y B 1$ and $m c y C$, as suggested for Hapalosiphon hibernicus and Anabaena strain 18B6 [3]. If the ancestral McyB1 A domain was C-like, some Microcystis strains must have obtained a novel McyB1 A domain, presumably through recombination with a different NRPS gene cluster. Recently, the presence of a Leuactivating, B-type McyB1 A domain was reported in two Nostoc strains [3] and this may in contrast strengthen the hypothesis that the ancestral A domain in McyB1 was Btype. However, the B-type A domain sequences from Microcystis and Nostoc seem to be separated by rather long phylogenetic distances, suggesting that these A domains were introduced in the McyB1 module by two independent recombination events [3]. Clearly, further studies are needed to clarify the evolutionary history of the McyB1 A domain.

\section{Genomic processes reshaping the adenylation domains of McyBI and McyC}

Our results suggest that recombinations as well as point mutations contribute to variation in the A domains of modules McyB1 and McyC. Within Anabaena and Microcystis, frequent recombination was suggested both within and between $m c y B 1$ and $m c y C$ sequences (Figures 3, 4 and 5 , Tables 4 and 5). The low sequence variation $(0-1.2 \%)$ within Planktothrix mcyC sequences makes it difficult to detect recombination, since for the majority of methods, a minimum sequence variation of $5 \%$ is necessary to obtain substantial power [26]. The large sequence divergence between Planktothrix $m c y B 1$ and $m c y C$ sequences might prevent homology-driven recombination, which requires a relatively high level of sequence similarity between the donor and recipient DNA. In Planktothrix, the longest identical DNA segment shared by $m c y B 1$ and $m c y C$ (18 bp) may be too short for initiation of RecA-mediated recombination [27-29]. Within Anabaena and Microcystis, the high sequence similarity between these gene segments appears to be maintained by frequent recombination 
Table 4: Recombination detected within mcyBI and mcyC data sets by RPD, GENECONV and MAXCHI2

\begin{tabular}{|c|c|c|c|c|}
\hline \multirow[t]{2}{*}{ Strains involved } & \multirow{2}{*}{$\begin{array}{c}\text { RDP } \\
\text { fragment, } \\
P \text { value }\end{array}$} & \multicolumn{2}{|c|}{ GENECONV } & \multirow{2}{*}{$\begin{array}{c}\text { MaxChi, } \\
\text { fragment, } \\
P \text { value }\end{array}$} \\
\hline & & $\begin{array}{c}(g=I) \\
\text { fragment, } \\
P \text { value }\end{array}$ & $\begin{array}{c}(g=0) \\
\text { fragment, } \\
P \text { value }\end{array}$ & \\
\hline \multicolumn{5}{|c|}{ Putative recombination events detected within mcyBI } \\
\hline \multicolumn{5}{|l|}{ Anabaena } \\
\hline $\begin{array}{l}318(B I R 246, N-C 269 / 2, N-C 269 / 6) \\
66 \text { A }\end{array}$ & $\begin{array}{l}102-594 \\
0.0015\end{array}$ & $\begin{array}{c}102-594 \\
0.008\end{array}$ & -- & -- \\
\hline $\begin{array}{l}18 B 6 \\
288\end{array}$ & $\begin{array}{l}17-457 \\
<0.00 \mid\end{array}$ & $\begin{array}{l}17-457 \\
0.013\end{array}$ & -- & $\begin{array}{l}17-457 \\
<0.00 \mid\end{array}$ \\
\hline $\begin{array}{l}\text { 66A (3I5, BIR246) } \\
\text { ITU30S4 }\end{array}$ & $\begin{array}{l}828-1062 \\
<0.001\end{array}$ & $\begin{array}{c}828-1062 \\
0.026\end{array}$ & $\begin{array}{l}828-1062 \\
<0.001\end{array}$ & -- \\
\hline $\begin{array}{l}\text { N-C } 269 / 6(\mathrm{~N}-\mathrm{C} 269 / 2,315) \\
\text { I8B6 (ITU44SI6) }\end{array}$ & $\begin{array}{l}528-742 \\
0.05\end{array}$ & $\begin{array}{c}528-742 \\
<0.001\end{array}$ & $\begin{array}{l}528-742 \\
<0.001\end{array}$ & $\begin{array}{c}528-742 \\
<0.001\end{array}$ \\
\hline $\begin{array}{l}\text { N-C 83/I (ITU3IS9, ITU30S4) } \\
\text { ITU46SI I }\end{array}$ & $\begin{array}{l}777-858 \\
<0.001\end{array}$ & $\begin{array}{l}777-858 \\
<0.001\end{array}$ & -- & -- \\
\hline $\begin{array}{l}315 \\
288\end{array}$ & $\begin{array}{l}725-997 \\
0.016\end{array}$ & $\begin{array}{l}725-997 \\
0.0015\end{array}$ & $\begin{array}{l}725-997 \\
<0.001\end{array}$ & $\begin{array}{l}725-997 \\
<0.001\end{array}$ \\
\hline \multicolumn{5}{|l|}{ Microcystis } \\
\hline $\begin{array}{l}\text { N-C } 357 \text { (N-C 57, N-C 143, N-C 228/I) } \\
\text { NIES } 102\end{array}$ & $\begin{array}{l}879-925 \\
<0.001\end{array}$ & $\begin{array}{l}879-925 \\
<0.001\end{array}$ & $\begin{array}{l}879-925 \\
<0.001\end{array}$ & $\begin{array}{l}879-925 \\
<0.001\end{array}$ \\
\hline \multicolumn{5}{|l|}{ Planktothrix } \\
\hline $\begin{array}{l}\text { CCAP } 1459 / 30 \\
31 / 1\end{array}$ & $\begin{array}{c}393-606 \\
0.026\end{array}$ & -- & -- & $\begin{array}{c}393-606 \\
0.006\end{array}$ \\
\hline $\begin{array}{l}\text { I I I }(3,64) \\
\text { SAG } 6.89\end{array}$ & $\begin{array}{c}755-843 \\
0.008\end{array}$ & $\begin{array}{c}607-884 \\
0.048\end{array}$ & $\begin{array}{c}607-884 \\
0.02\end{array}$ & -- \\
\hline $\begin{array}{l}79 \\
\text { CCAP } 1459 / 30\end{array}$ & $\begin{array}{c}567-843 \\
0.0125\end{array}$ & -- & $\begin{array}{c}520-877 \\
0.013\end{array}$ & $\begin{array}{c}550-843 \\
<0.001\end{array}$ \\
\hline $\begin{array}{l}79 \\
31 / 1\end{array}$ & $\begin{array}{c}878-1050 \\
0.016\end{array}$ & $\begin{array}{c}875-1080 \\
0.05\end{array}$ & $\begin{array}{c}875-1080 \\
0.016\end{array}$ & -- \\
\hline $\begin{array}{l}\text { N-C } 126 / 8 \\
80\end{array}$ & -- & $\begin{array}{c}520-877 \\
0.05\end{array}$ & $\begin{array}{c}520-877 \\
0.009\end{array}$ & $\begin{array}{c}550-843 \\
<0.001\end{array}$ \\
\hline
\end{tabular}

Putative recombination events detected within mcyC

\begin{tabular}{|c|c|c|c|c|}
\hline Anabaena & -- & -- & -- & -- \\
\hline \multicolumn{5}{|l|}{ Microcystis } \\
\hline $\begin{array}{l}\text { N-C } 161 / 1 \text { (N-C 17I//10, N-C 324/I, N-C 264) } \\
\text { N-C 228/I }\end{array}$ & $\begin{array}{l}1-203 \\
0.0016\end{array}$ & $\begin{array}{l}1-246 \\
0.019\end{array}$ & -- & -- \\
\hline Planktothrix & -- & -- & -- & -- \\
\hline
\end{tabular}

Events detected by two or more methods are listed.

events. Recombination between different domains, such as $m c y B 1$ and $m c y C$, has in some cases lead to replacement of a nearly entire A domain (in Anabaena 18B6) and in others to replacement of a functionally important part of the domain in McyB1 (in Microcystis N-C 264) (Figure 3). In both cases this has resulted in a change of functionality (i.e. amino acid activated) and subsequent production of microcystin-RR.
Our results, together with previous reports $[3,11,15]$, indicate that various types of recombination lead to a continual restyling (remodelling) of the adenylation domains of microcystin synthetase. Recombination within a single domain appears to be frequent and may have little impact on the type of amino acid activated. Recombination between $m c y B 1$ and $m c y C$ appears to be frequent in some genera and may result in changes in the microcystin pro- 
Table 5: Recombination detected between mcyBI and mcyC by RPD, GENECONV and MAXCHI2

\begin{tabular}{|c|c|c|c|c|}
\hline \multirow[t]{2}{*}{ Strains involved } & \multirow{2}{*}{$\begin{array}{l}\text { RDP } \\
\text { fragment, } \\
P \text { value }\end{array}$} & \multicolumn{2}{|c|}{ GENECONV } & \multirow{2}{*}{$\begin{array}{l}\text { MaxChi, } \\
\text { fragment, } \\
P \text { value }\end{array}$} \\
\hline & & $\begin{array}{l}(g=1) \\
\text { fragment, } \\
P \text { value }\end{array}$ & $\begin{array}{l}(g=0) \\
\text { fragment, } \\
P \text { value }\end{array}$ & \\
\hline \multicolumn{5}{|l|}{ Anabaena } \\
\hline $\begin{array}{l}\text { McyB I } 288 \\
\text { McyC } 66 \text { A }\end{array}$ & -- & $\begin{array}{l}132-426 \\
0.001\end{array}$ & $\begin{array}{l}132-429 \\
<0.00 \mid\end{array}$ & $\begin{array}{l}\mid 32-426 \\
<0.00 \mid\end{array}$ \\
\hline $\begin{array}{l}\text { McyB I ITU44SI6 } \\
\text { McyC 66A } \\
(\text { I8B6, } 90,318,258,202 \mathrm{AI} / 35, \text { ITU44SI6, ITU32SII, 288, 202A2/4I, 0TU33SI6, } \\
315, \text { BIR246, N-C 267/4, N-C 269/2, N-C 269/6) }\end{array}$ & $\begin{array}{l}742-864 \\
<0.001\end{array}$ & $\begin{array}{l}742-864 \\
<0.001\end{array}$ & -- & $\begin{array}{l}742-864 \\
<0.001\end{array}$ \\
\hline $\begin{array}{l}\text { McyB I st } 288 \\
\text { McyC } 202 \mathrm{Al} / 35(202 \mathrm{~A} 2 / 4 \mathrm{I})\end{array}$ & -- & $\begin{array}{c}311-432 \\
0.0014\end{array}$ & $\begin{array}{l}311-432 \\
0.0011\end{array}$ & $\begin{array}{l}311-432 \\
<0.001\end{array}$ \\
\hline $\begin{array}{l}\text { McyB I ITU46SII } \\
\text { McyC N-C 83/I (N-C 270/I) }\end{array}$ & $\begin{array}{l}742-864 \\
<0.001\end{array}$ & $\begin{array}{l}742-864 \\
<0.001\end{array}$ & -- & -- \\
\hline $\begin{array}{l}\text { McyB I } 258 \\
\text { McyC N-C } 269 / 6\end{array}$ & -- & $\begin{array}{l}103-456 \\
0.001\end{array}$ & $\begin{array}{l}103-456 \\
<0.001\end{array}$ & $\begin{array}{l}80-599 \\
<0.001\end{array}$ \\
\hline \multicolumn{5}{|l|}{ Microcystis } \\
\hline $\begin{array}{l}\text { McyB I N-C } 264 \\
\text { McyC N-C } 31 \text { (N-C 57, N-C I40, N-C I43, N-C I60/2) }\end{array}$ & $\begin{array}{l}\text { I-279, } \\
879-1062 \\
<0.001\end{array}$ & $\begin{array}{l}\text { I-279, } \\
879-1062 \\
<0.001\end{array}$ & $\begin{array}{l}36-210 \\
<0.001\end{array}$ & -- \\
\hline $\begin{array}{l}\text { McyB I N-C } 264 \\
\text { McyC N-C } 31 \text { (N-C 57, N-C 357) }\end{array}$ & $\begin{array}{l}707-918 \\
<0.001\end{array}$ & $\begin{array}{l}707-918 \\
<0.001\end{array}$ & $\begin{array}{l}795-1056 \\
0.0013\end{array}$ & $\begin{array}{l}707-918 \\
<0.001\end{array}$ \\
\hline $\begin{array}{l}\text { McyB I N-C } 264 \\
\text { McyC N-C } 161 / 1\end{array}$ & $\begin{array}{l}270-795 \\
<0.001\end{array}$ & $\begin{array}{l}262-765 \\
<0.001\end{array}$ & -- & $\begin{array}{l}236-1056 \\
<0.001\end{array}$ \\
\hline $\begin{array}{l}\text { McyB I N-C } 264 \\
\text { McyC N-C } 169 / 7 \text { (N-C I7I/10 N-C 264, N-C 357, N-C 496) }\end{array}$ & $\begin{array}{l}\text { I-279, } \\
879-1062 \\
<0.001\end{array}$ & $\begin{array}{l}3-270 \\
879-1062 \\
<0.001\end{array}$ & $\begin{array}{l}3-270 \\
<0.001\end{array}$ & $\begin{array}{l}3-270 \\
<0.001\end{array}$ \\
\hline $\begin{array}{l}\text { McyB I N-C } 264 \\
\text { McyC N-C I7I/10 (N-C 324/I, UV027, N-C I40, N-C I43, N-C 160/2) }\end{array}$ & $\begin{array}{l}466-782 \\
0.00105\end{array}$ & $\begin{array}{l}466-782 \\
0.009\end{array}$ & $\begin{array}{l}466-782 \\
<0.001\end{array}$ & -- \\
\hline $\begin{array}{l}\text { McyB I N-C } 264 \\
\text { McyC N-C 228/I }\end{array}$ & -- & $\begin{array}{l}36-210 \\
<0.001\end{array}$ & -- & $\begin{array}{l}36-210 \\
<0.001\end{array}$ \\
\hline $\begin{array}{l}\text { McyB I N-C } 264 \\
\text { McyC N-C 228/I }\end{array}$ & $\begin{array}{l}319-766 \\
<0.001\end{array}$ & $\begin{array}{l}319-766 \\
<0.001\end{array}$ & -- & $\begin{array}{l}319-766 \\
<0.001\end{array}$ \\
\hline $\begin{array}{l}\text { McyB I N-C I69/7 } \\
\text { McyC N-C } 496\end{array}$ & -- & $\begin{array}{l}238-469 \\
<0.001\end{array}$ & -- & $\begin{array}{l}238-469 \\
<0.001\end{array}$ \\
\hline $\begin{array}{l}\text { McyB I N-C } 264 \\
\text { McyC N-C 496, UV027, K-139, PCC7806 }\end{array}$ & -- & $\begin{array}{l}3-270 \\
<0.001\end{array}$ & $\begin{array}{l}3-270 \\
<0.001\end{array}$ & $\begin{array}{l}3-270 \\
<0.001\end{array}$ \\
\hline $\begin{array}{l}\text { McyB I N-C } 57 \\
\text { McyC N-C I } 43, \text { K-I } 39\end{array}$ & $\begin{array}{l}444-769 \\
<0.001\end{array}$ & $\begin{array}{l}444-769 \\
<0.001\end{array}$ & $\begin{array}{l}444-769 \\
<0.001\end{array}$ & -- \\
\hline $\begin{array}{l}\text { McyB I N-C I69/7 } \\
\text { McyC K-I39 }\end{array}$ & $\begin{array}{l}707-915 \\
<0.001\end{array}$ & $\begin{array}{l}707-915 \\
<0.001\end{array}$ & -- & -- \\
\hline $\begin{array}{l}\text { McyB I N-C } 357 \\
\text { McyC N-C } 264\end{array}$ & -- & $\begin{array}{l}368-779 \\
<0.001\end{array}$ & -- & $\begin{array}{c}368-779 \\
<0.001\end{array}$ \\
\hline $\begin{array}{l}\text { McyB I N-C } 357 \\
\text { McyC N-C } 171 / 10\end{array}$ & -- & $\begin{array}{l}879-925 \\
<0.001\end{array}$ & -- & $\begin{array}{l}879-925 \\
<0.001\end{array}$ \\
\hline $\begin{array}{l}\text { McyB I N-C 228/I (NIESI02) } \\
\text { McyC N-C I60/2 (N-C I43) }\end{array}$ & $\begin{array}{c}368-779 \\
<0.001\end{array}$ & $\begin{array}{c}368-779 \\
<0.001\end{array}$ & $\begin{array}{c}368-792 \\
<0.001\end{array}$ & -- \\
\hline Planktothrix & -- & -- & -- & -- \\
\hline
\end{tabular}

Events detected by two or more methods are listed.

file of the recombinant strains. Successful recombination between A domain regions from different NRPS gene clusters $[14,15]$ were found to be infrequent in the strains investigated here.
Positive selection in the adenylation domains of McyBI and McyC

Overall, the adenylation domains of McyB1 and McyC seem to be under purifying selection, as shown previously 

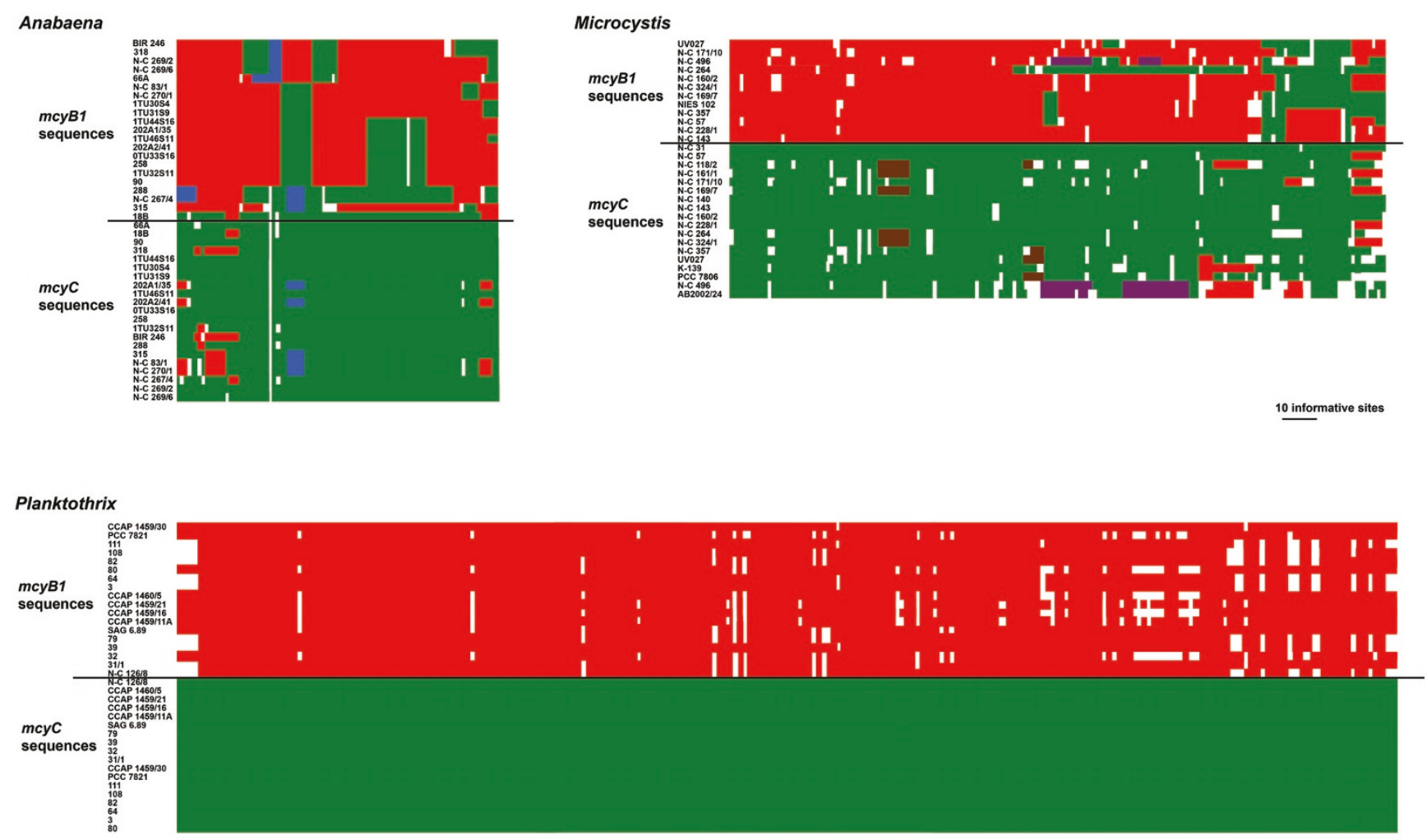

Figure 3

Informative sites in Anabaena, Microcystis and Planktothrix mcyB IC data sets. Informative sites are defined as positions with at least two different nucleotides in which each of the variants occurs at least twice. Identical nucleotides have the same colour and the colours thus display phylogenetic affinity.

for other segments of the mcy gene cluster $[11,12,21]$, indicating that mutations that affect the amino acid sequence of these domains generally are deleterious. However, the $\omega$-values $(0.2-0.49)$ observed in this study are relatively high compared to $\omega$-values reported for several cyanobacterial house keeping genes (mainly below 0.1 ) [30], implying a relaxation of selective constraints.

Amino acid residues in the A domains of McyB1 and $\mathrm{McyC}$ that seem to be under positive selective pressure are located throughout the entire analyzed sequence (Figure 7). Among the positively selected amino acids, residues included in binding pocket signatures are particularly interesting, since they may influence the active site selectivity [31,32]. The amino acid change Phe $\rightarrow$ Cys in binding pocket position 278 (Table 6) in the McyB1 sequences of Anabaena is an example of this. According to the peptide profiles of the Anabaena strains (Table 1), this change is associated with the incorporation of Hty/Leu, rather than only Leu (or Leu/Arg). Also, the Leu $\rightarrow$ Phe exchange at the binding pocket position 278 in the McyB1 sequences of Planktothrix (Table 6) is associated with a change in incorporation from Hty to Arg. One could hypothesize that positive selection of these and other residues in the synthetases reflect selection of a particular peptide profile produced by the corresponding strains. Such a causative relationship between these specific genetic changes and phenotypic effects remains to be demonstrated.

Interestingly, a binding pocket residue under positive selection is also present in the McyC sequences of Anabaena (Figure 7). Since all McyC modules studied here mainly incorporate Arg, the selection seemingly does not concern gross substrate specificity. Other properties, like NRPS catalytic efficiency or the ability to produce minor variants, might be the properties selected for. Also in McyB1 sequences from all genera there are several positively selected amino acid residues not associated with substrate selectivity, indicating that some other property is selected for in these A domains. This could for instance again be changes in the catalytic efficiency or in the interactions between neighboring domains and modules.

Sequence comparisons show that the A domain of McyC is more conserved than the McyB1 A domain - also 

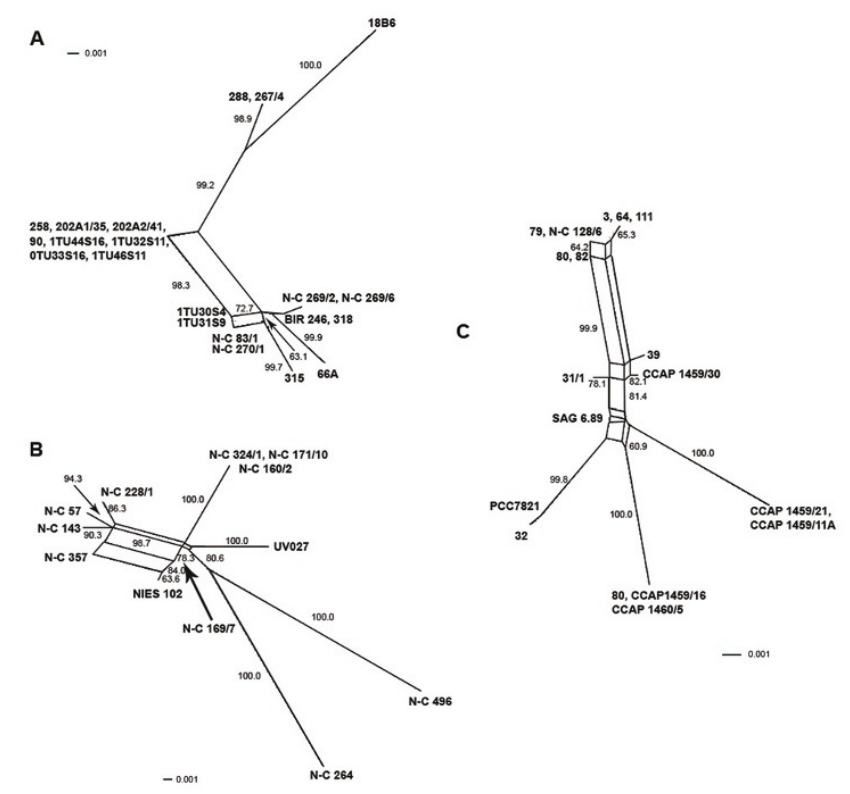

\section{Figure 4}

Splits decomposition analysis of adenylation domain encoding sequences of $\mathbf{m c y} B \boldsymbol{I}$. Shown are Anabaena (A), Microcystis (B) and Planktothrix (C). Bootstrap values over $50 \%$ are shown.

$A$

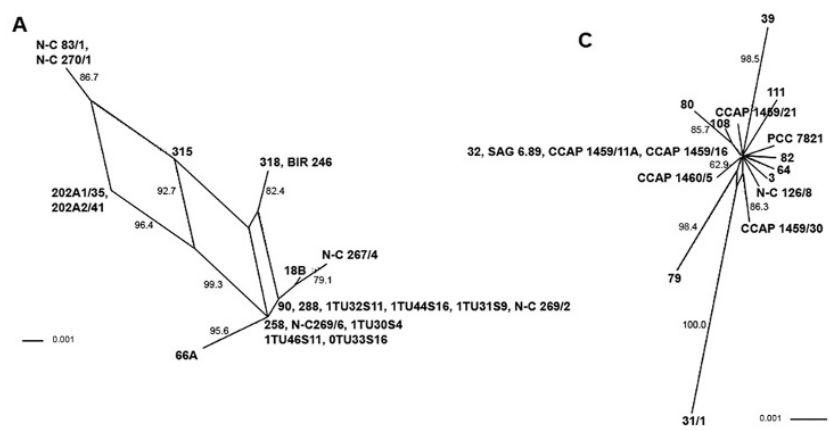

B

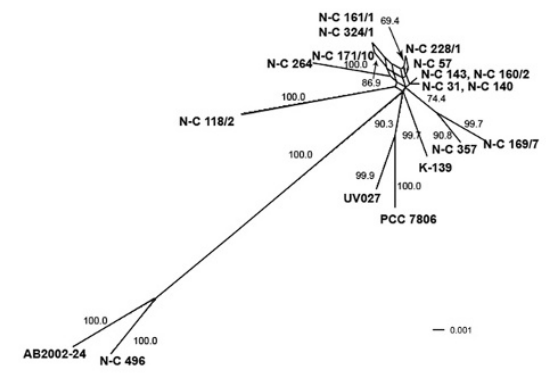

\section{Figure 5}

Splits decomposition analysis of adenylation domain encoding sequences of mcyC. Shown are Anabaena (A), Microcystis (B) and Planktothrix (C). Bootstrap values over $50 \%$ are shown.
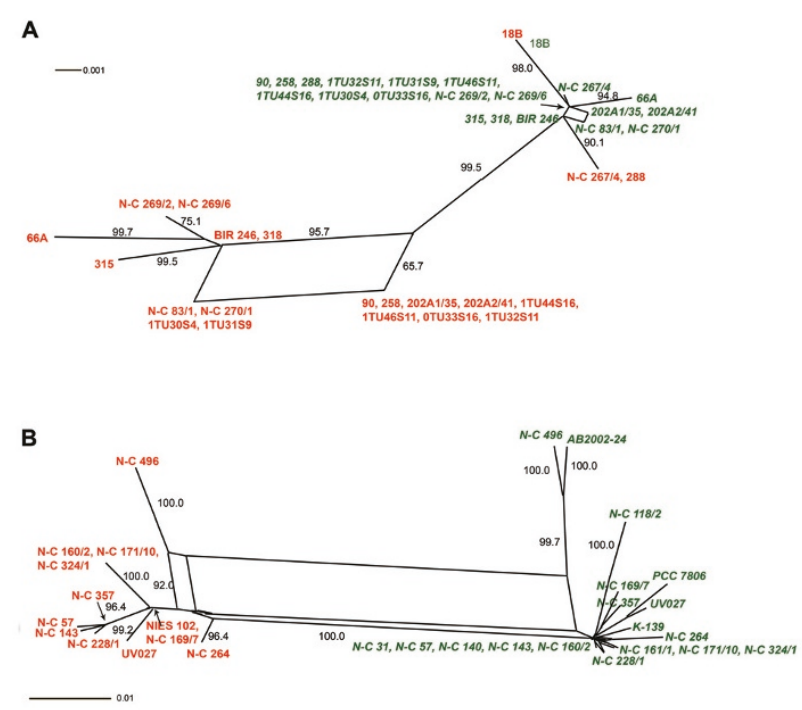

C

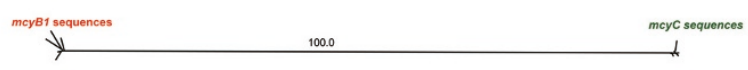

Figure 6

Splits decomposition analysis of adenylation domain encoding sequences of $m c y B I$ and mcyC. Shown are Anabaena (A), Microcystis (B) and Planktothrix (C). mcyBI and $m c y C$ sequences are indicated by red and green, respectively. Bootstrap values above $50 \%$ are shown. Within mcyC sequences of Microcystis, all branches have bootstrap values ranging from $88-100 \%$.

reflected by the lack of amino acid variation in position $\mathrm{Z}$ of the produced peptides. Within Planktothrix, a lower recombination rate and stronger purifying selection compared to Anabaena and Microcystis indicate stronger functional constraints.

\section{Conclusion}

Our results revealed no clear indications of recombination across the genera, while frequent recombination events both within and between $m c y B$ and $m c y C$ sequences were detected between strains from same genus, except for $m c y C$ from Planktothrix. We demonstrate remodelling of $m c y B$ and $m c y C$ genes including evidence for positive selection acting at some sites, indicating that the microcystin variant profile of a given strain is likely to influence the ability of the strain to interact with its environment. 
Table 6: Binding pocket signatures identified in A domain sequences.

\begin{tabular}{|c|c|c|c|c|c|c|c|c|c|c|c|c|c|c|c|c|c|c|c|c|}
\hline \multirow[t]{3}{*}{ Strain } & \multicolumn{10}{|c|}{ Adenylation domain of McyB I } & \multicolumn{10}{|c|}{ Adenylation domain of McyC } \\
\hline & \multicolumn{9}{|c|}{ Binding pocket residues } & \multirow{2}{*}{$\begin{array}{l}\text { Substrate } \\
*\end{array}$} & \multicolumn{9}{|c|}{ Binding pocket residues } & \multirow{2}{*}{$\begin{array}{l}\text { Substra } \\
\text { te* }\end{array}$} \\
\hline & 235 & 236 & 239 & 278 & 299 & 301 & 322 & 330 & 331 & & 235 & 236 & 239 & 278 & 299 & 301 & 322 & 330 & 331 & \\
\hline \multicolumn{21}{|l|}{ Anabaena } \\
\hline N-C 83/I & $D$ & $\mathrm{~V}$ & W & $\mathbf{F}$ & $\mathrm{F}$ & G & $\mathrm{L}$ & V & D & Leu, Arg & $\mathrm{D}$ & V & W & $\mathbf{S}$ & $\mathrm{F}$ & G & $\mathrm{L}$ & V & $\mathrm{D}$ & Arg \\
\hline N-C 267/4 & $\mathrm{D}$ & V & W & C & $\mathrm{F}$ & G & $\mathrm{L}$ & $\mathrm{V}$ & $\mathbf{Y}$ & $\begin{array}{l}\text { Hty, Leu, } \\
\text { Phe, Hil, } \\
\text { Hph }\end{array}$ & $\mathrm{D}$ & $\mathrm{V}$ & W & $\mathbf{S}$ & $\mathrm{F}$ & G & $\mathrm{L}$ & $\mathrm{V}$ & $\mathrm{D}$ & Arg \\
\hline $\mathrm{N}-\mathrm{C} 269 / 2$ & $\mathrm{D}$ & V & W & c & $\mathrm{F}$ & G & $\mathrm{L}$ & V & $\mathbf{Y}$ & $\begin{array}{l}\text { Hty, Leu, } \\
\text { Phe, Hil, } \\
\text { Hph }\end{array}$ & $\mathrm{D}$ & V & W & c & $\mathrm{F}$ & G & $\mathrm{L}$ & V & $\mathrm{D}$ & Arg \\
\hline N-C 269/6 & $D$ & V & w & C & $\mathrm{F}$ & G & $\mathrm{L}$ & V & $\mathbf{Y}$ & $\begin{array}{l}\text { Hty, Leu, } \\
\text { Phe, Hil, } \\
\text { Hph }\end{array}$ & $\mathrm{D}$ & V & W & C & $\mathrm{F}$ & G & $\mathrm{L}$ & V & $D$ & Arg \\
\hline N-C 270/I & $D$ & V & w & $\mathbf{F}$ & $\mathrm{F}$ & G & $\mathrm{L}$ & V & D & Leu, Arg & $\mathrm{D}$ & V & W & $\mathbf{S}$ & $\mathrm{F}$ & G & $\mathrm{L}$ & V & $D$ & Arg \\
\hline 90 & $\mathrm{D}$ & V & $w$ & $\mathbf{F}$ & $\mathrm{F}$ & G & $\mathrm{L}$ & V & D & Leu, Arg & $\mathrm{D}$ & V & W & C & $\mathrm{F}$ & G & $\mathrm{L}$ & V & $\mathrm{D}$ & Arg \\
\hline ITU44SI6 & $D$ & V & $w$ & $\mathbf{F}$ & $\mathrm{F}$ & G & $\mathrm{L}$ & $\mathrm{V}$ & D & Leu & $\mathrm{D}$ & $\mathrm{V}$ & W & C & $\mathrm{F}$ & G & $\mathrm{L}$ & V & $D$ & Arg \\
\hline ITU30S4 & $D$ & V & W & $\mathbf{F}$ & $\mathrm{F}$ & G & $\mathrm{L}$ & V & D & Leu & $\mathrm{D}$ & V & W & C & $\mathrm{F}$ & G & $\mathrm{L}$ & V & $D$ & Arg \\
\hline ITU3IS9 & $\mathrm{D}$ & V & w & $\mathbf{F}$ & $\mathrm{F}$ & G & $\mathrm{L}$ & V & D & Leu & $\mathrm{D}$ & V & w & C & $\mathrm{F}$ & G & $\mathrm{L}$ & V & $\mathrm{D}$ & Arg \\
\hline $202 \mathrm{Al} / 35$ & $D$ & V & w & $\mathbf{F}$ & $\mathrm{F}$ & G & $\mathrm{L}$ & $\mathrm{V}$ & D & Leu & $\mathrm{D}$ & $\mathrm{V}$ & W & $\mathbf{s}$ & $\mathrm{F}$ & $\mathrm{G}$ & $\mathrm{L}$ & V & $\mathrm{D}$ & Arg \\
\hline ITU46SII & $D$ & V & W & $\mathbf{F}$ & $\mathrm{F}$ & G & $\mathrm{L}$ & V & D & Leu & $\mathrm{D}$ & V & W & C & $\mathrm{F}$ & G & $\mathrm{L}$ & V & $D$ & Arg \\
\hline $202 \mathrm{~A} / 4 \mathrm{I}$ & $\mathrm{D}$ & V & $w$ & $\mathbf{F}$ & $\mathrm{F}$ & G & $\mathrm{L}$ & V & D & Leu & $\mathrm{D}$ & V & w & $\mathbf{S}$ & $\mathrm{F}$ & G & $\mathrm{L}$ & V & $\mathrm{D}$ & Arg \\
\hline 0TU33SI6 & $D$ & V & W & $\mathbf{F}$ & $\mathrm{F}$ & G & $\mathrm{L}$ & V & D & Leu & $D$ & V & W & C & $\mathrm{F}$ & G & $\mathrm{L}$ & V & $D$ & Arg \\
\hline 258 & $D$ & V & W & $\mathbf{F}$ & $\mathrm{F}$ & G & $\mathrm{L}$ & V & D & Leu & $\mathrm{D}$ & V & W & C & $\mathrm{F}$ & G & $\mathrm{L}$ & V & $D$ & Arg \\
\hline ITU32SII & $\mathrm{D}$ & V & w & $\mathbf{F}$ & $\mathrm{F}$ & G & $\mathrm{L}$ & V & D & Leu & $\mathrm{D}$ & V & w & $\mathbf{s}$ & $\mathrm{F}$ & G & $\mathrm{L}$ & V & $\mathrm{D}$ & Arg \\
\hline BIR 246 & $D$ & V & w & C & $\mathrm{F}$ & G & $\mathrm{L}$ & V & $\mathbf{Y}$ & $\begin{array}{l}\text { Hty, Leu, } \\
\text { Hil, Phe, } \\
\text { Hph }\end{array}$ & $\mathrm{D}$ & V & W & C & $\mathrm{F}$ & G & $\mathrm{L}$ & V & $D$ & Arg \\
\hline 288 & $\mathrm{D}$ & V & W & C & $\mathrm{F}$ & G & $\mathrm{L}$ & V & $\mathbf{Y}$ & $\begin{array}{l}\text { Hty, Leu, } \\
\text { Phe, Hph }\end{array}$ & $\mathrm{D}$ & V & W & $\mathbf{S}$ & $\mathrm{F}$ & G & $\mathrm{L}$ & V & $D$ & Arg \\
\hline 315 & $D$ & V & w & $\mathbf{S}$ & $\mathrm{F}$ & G & $\mathrm{L}$ & $\mathrm{V}$ & $\mathbf{Y}$ & Leu, Hty & $\mathrm{D}$ & V & W & $\mathbf{S}$ & $\mathrm{F}$ & G & $\mathrm{L}$ & V & $\mathrm{D}$ & Arg \\
\hline 318 & $D$ & V & W & C & $\mathrm{F}$ & G & $\mathrm{L}$ & $\mathrm{V}$ & $\mathbf{Y}$ & Hty, Leu & $\mathrm{D}$ & $\mathrm{V}$ & W & C & $\mathrm{F}$ & G & $\mathrm{L}$ & $\mathrm{V}$ & $D$ & Arg \\
\hline $66 \mathrm{~A}$ & $D$ & V & W & $\mathbf{S}$ & $\mathrm{F}$ & G & $\mathrm{L}$ & $\mathrm{V}$ & $\mathbf{Y}$ & $\begin{array}{l}\text { Hph, Hty, } \\
\text { Leu }\end{array}$ & $D$ & $\mathrm{~V}$ & W & $\mathbf{S}$ & $F$ & G & $\mathrm{L}$ & $\mathrm{V}$ & $D$ & Arg \\
\hline $18 \mathrm{~B} 6$ & $D$ & $\mathrm{~V}$ & w & $\mathbf{S}$ & $\mathrm{F}$ & G & $\mathrm{L}$ & V & D & Arg & $D$ & $\mathrm{~V}$ & w & $\mathbf{S}$ & $\mathrm{F}$ & G & $\mathrm{L}$ & $\mathrm{V}$ & $D$ & Arg \\
\hline
\end{tabular}


Table 6: Binding pocket signatures identified in A domain sequences. (Continued)

\begin{tabular}{|c|c|c|c|c|c|c|c|c|c|c|c|c|c|c|c|c|c|c|c|c|}
\hline $\mathrm{N}-\mathrm{C} I \mathrm{I} / \mathrm{2} / 2$ & & & & & & & & & & & $\mathrm{D}$ & $\mathrm{V}$ & $\mathrm{W}$ & $\mathrm{T}$ & $\mathrm{I}$ & $\mathrm{G}$ & $A$ & $\mathrm{~V}$ & $\mathrm{D}$ & Arg \\
\hline N-C 140 & & & & & & & & & & & $D$ & $\mathrm{~V}$ & $w$ & $\mathrm{~T}$ & 1 & G & $A$ & $\mathrm{~V}$ & $D$ & Arg \\
\hline $\mathrm{N}-\mathrm{C} 143$ & $D$ & G & $w$ & $\mathrm{~T}$ & I & G & $A$ & $\mathrm{~V}$ & $\mathbf{E}$ & None & $D$ & V & w & $\mathrm{T}$ & 1 & $\mathrm{G}$ & $A$ & $\mathrm{~V}$ & $D$ & Arg \\
\hline $\mathrm{N}-\mathrm{C} 160 / 2$ & $\mathrm{D}$ & G & W & $\mathrm{T}$ & I & G & $A$ & V & $\mathbf{E}$ & None & $\mathrm{D}$ & V & W & $\mathrm{T}$ & 1 & G & $A$ & $\mathrm{~V}$ & $D$ & Arg \\
\hline $\mathrm{N}-\mathrm{C} 16 \mathrm{I} / \mathrm{I}$ & & & & & & & & & & & $D$ & $\mathrm{~V}$ & $w$ & $\mathrm{~T}$ & 1 & G & A & $\mathrm{V}$ & $D$ & Arg \\
\hline $\mathrm{N}-\mathrm{C} 169 / 7$ & $D$ & G & $w$ & $\mathrm{~T}$ & I & G & $A$ & $\mathrm{~V}$ & $\mathbf{E}$ & Arg, Leu & $D$ & V & w & $\mathrm{T}$ & 1 & $\mathrm{G}$ & $A$ & $\mathrm{~V}$ & $D$ & Arg \\
\hline $\mathrm{N}-\mathrm{C} 171 / 10$ & $\mathrm{D}$ & G & W & $\mathrm{T}$ & I & G & A & $\mathrm{V}$ & $\mathbf{E}$ & $\begin{array}{l}\text { Leu, Arg, } \\
\text { Tyr }\end{array}$ & $D$ & $\mathrm{~V}$ & W & $\mathrm{T}$ & 1 & G & $A$ & $\mathrm{~V}$ & $D$ & Arg \\
\hline $\mathrm{N}-\mathrm{C} 228 / \mathrm{I}$ & $D$ & G & $w$ & $\mathrm{~T}$ & I & G & A & $\mathrm{V}$ & $\mathbf{E}$ & Arg, Leu & $\mathrm{D}$ & $\mathrm{V}$ & w & $\mathrm{T}$ & 1 & $\mathrm{G}$ & $A$ & $\mathrm{~V}$ & $D$ & Arg \\
\hline N-C 264 & $\mathrm{D}$ & $\mathbf{v}$ & $w$ & $\mathrm{~T}$ & 1 & G & $A$ & V & D & Arg & $D$ & $\mathrm{~V}$ & w & $\mathrm{T}$ & 1 & G & $A$ & $\mathrm{~V}$ & $D$ & Arg \\
\hline N-C 324/I & $D$ & G & $w$ & $\mathrm{~T}$ & 1 & G & $A$ & $\mathrm{~V}$ & $\mathbf{E}$ & Arg, Leu & $D$ & $\mathrm{~V}$ & $w$ & $\mathrm{~T}$ & 1 & G & A & $\mathrm{V}$ & $D$ & Arg \\
\hline N-C 357 & $D$ & G & $w$ & $\mathrm{~T}$ & 1 & G & $A$ & $\mathrm{~V}$ & $\mathbf{E}$ & $\begin{array}{l}\text { Arg, Leu, } \\
\text { Tyr }\end{array}$ & $D$ & $\mathrm{~V}$ & $w$ & $\mathrm{~T}$ & 1 & G & $A$ & $\mathrm{~V}$ & $D$ & Arg \\
\hline N-C 496 & $\mathrm{D}$ & G & $w$ & $\mathrm{~T}$ & 1 & G & $A$ & V & $\mathbf{E}$ & Tyr & $D$ & $\mathrm{~V}$ & w & $\mathrm{T}$ & 1 & G & $A$ & $\mathrm{~V}$ & $D$ & Arg \\
\hline AB2002-24 & & & & & & & & & & & $D$ & V & w & $\mathrm{T}$ & 1 & $\mathrm{G}$ & $A$ & $\mathrm{~V}$ & $D$ & Arg \\
\hline UV027 & $D$ & $\mathbf{v}$ & $w$ & $\mathrm{~T}$ & I & G & $A$ & $\mathrm{~V}$ & $\mathbf{E}$ & Arg & $D$ & $\mathrm{~V}$ & $w$ & $\mathrm{~T}$ & 1 & G & $A$ & $\mathrm{~V}$ & $D$ & Arg \\
\hline PCC7806 & & & & & & & & & & & $D$ & $\mathrm{~V}$ & w & $\mathrm{T}$ & 1 & G & $A$ & $\mathrm{~V}$ & $D$ & Arg \\
\hline$K-139$ & & & & & & & & & & & $D$ & $\mathrm{~V}$ & w & $\mathrm{T}$ & 1 & $\mathrm{G}$ & $A$ & $\mathrm{~V}$ & $D$ & Arg \\
\hline NIESIO2 & $D$ & G & $w$ & $\mathrm{~T}$ & 1 & G & A & $\mathrm{V}$ & $\mathbf{E}$ & $\begin{array}{l}\text { Leu, Arg, } \\
\text { Tyr }\end{array}$ & $D$ & $\mathrm{~V}$ & $w$ & $\mathrm{~T}$ & 1 & G & $A$ & $\mathrm{~V}$ & $D$ & Arg \\
\hline
\end{tabular}

\section{Planktothrix}

3

II I

$31 / 1$

32

39

79

SAG 6.89

$\mathrm{N}-\mathrm{C} 126 / 8$

80

82

108

PCC782I

CCAPI $459 / 30$

CCAPI 459/IIA

CCAPI $459 / 21$

CCAPI $460 / 5$

CCAPI459/16

$\begin{array}{llllllll}\text { D } & \text { A } & \text { L } & \text { F } & \text { F } & \text { G } & \text { V } & \text { V } \\ \text { D } & \text { A } & \text { L } & \text { F } & \text { F } & \text { G } & \text { V } & \text { V } \\ \text { D } & \text { A } & \text { L } & \text { F } & \text { F } & \text { G } & \text { V } & \text { V } \\ \text { D } & \text { A } & \text { L } & \text { F } & \text { F } & \text { G } & \text { L } & \text { V } \\ \text { D } & \text { A } & \text { L } & \text { F } & \text { F } & \text { G } & \text { L } & \text { V } \\ \text { D } & \text { A } & \text { L } & \text { F } & \text { F } & \text { G } & \text { L } & \text { V } \\ \text { D } & \text { A } & \text { L } & \text { F } & \text { F } & \text { G } & \text { L } & \text { V } \\ \text { D } & \text { A } & \text { L } & \text { F } & \text { F } & \text { G } & \text { L } & \text { V } \\ \text { D } & \text { A } & \text { L } & \text { F } & \text { F } & \text { G } & \text { L } & \text { V } \\ \text { D } & \text { A } & \text { L } & \text { L } & \text { F } & \text { G } & \text { F } & \text { V } \\ \text { D } & \text { A } & \text { L } & \text { F } & \text { F } & \text { G } & \text { L } & \text { V } \\ & & & & & & & \\ \text { D } & \text { A } & \text { L } & \text { F } & \text { F } & \text { G } & \text { L } & \text { V } \\ \text { D } & \text { A } & \text { L } & \text { F } & \text { F } & \text { G } & \text { L } & \text { V } \\ \text { D } & \text { A } & \text { L } & \text { F } & \text { F } & \text { G } & \text { L } & \text { V } \\ \text { D } & \text { A } & \text { W } & \text { F } & \text { F } & \text { G } & \text { L } & \text { V } \\ \text { D } & \text { A } & \text { W } & \text { F } & \text { F } & \text { G } & \text { L } & \text { V } \\ \text { D } & \text { A } & \text { L } & \text { L } & \text { F } & \text { G } & \text { F } & \text { V } \\ \text { D } & \text { A } & \text { L } & \text { L } & \text { F } & \text { G } & \text { F } & \text { V }\end{array}$

$\begin{array}{ll}\text { D } & \text { Arg } \\ \text { D } & \text { Arg } \\ \text { D } & \text { Arg } \\ \text { D } & \text { Arg, Hty, } \\ & \text { Leu } \\ \text { D } & \text { Arg, Leu } \\ \text { D } & \text { Arg, Leu } \\ \text { D } & \text { Arg, Leu } \\ \text { D } & \text { Arg, Leu } \\ \text { D } & \text { Arg, Leu } \\ \text { A } & \text { Hty } \\ \text { D } & \text { Arg, Hty, } \\ & \text { Leu } \\ \text { D } & \text { Arg, Leu } \\ \text { D } & \text { Arg, Leu } \\ \text { D } & \text { Arg, Leu } \\ \text { D } & \text { Arg } \\ \text { D } & \text { Arg } \\ \text { A } & \text { Hty, Leu } \\ \text { A } & \text { Hty, Leu }\end{array}$

$\begin{array}{llllllllll}\text { D } & \text { P } & \text { W } & \text { G } & \text { F } & \text { G } & \text { L } & \text { V } & \text { D } & \text { Arg } \\ \text { D } & \text { P } & \text { W } & \text { G } & \text { F } & \text { G } & \text { L } & \text { V } & \text { D } & \text { Arg } \\ \text { D } & \text { P } & \text { W } & \text { G } & \text { F } & \text { G } & \text { L } & \text { V } & \text { D } & \text { Arg } \\ \text { D } & \text { P } & \text { W } & \text { G } & \text { F } & \text { G } & \text { L } & \text { V } & \text { D } & \text { Arg } \\ & & & & & & & & & \\ \text { D } & \text { P } & \text { W } & \text { G } & \text { F } & \text { G } & \text { L } & \text { V } & \text { D } & \text { Arg } \\ \text { D } & \text { P } & \text { W } & \text { G } & \text { F } & \text { G } & \text { L } & \text { V } & \text { D } & \text { Arg } \\ \text { D } & \text { P } & \text { W } & \text { G } & \text { F } & \text { G } & \text { L } & \text { V } & \text { D } & \text { Arg } \\ \text { D } & \text { P } & \text { W } & \text { G } & \text { F } & \text { G } & \text { L } & \text { V } & \text { D } & \text { Arg } \\ \text { D } & \text { P } & \text { W } & \text { G } & \text { F } & \text { G } & \text { L } & \text { V } & \text { D } & \text { Arg } \\ \text { D } & \text { P } & \text { W } & \text { G } & \text { F } & \text { G } & \text { L } & \text { V } & \text { N } & \text { Arg } \\ \text { D } & \text { P } & \text { W } & \text { G } & \text { F } & \text { G } & \text { L } & \text { V } & \text { D } & \text { Arg } \\ & & & & & & & & & \\ \text { D } & \text { P } & \text { W } & \text { G } & \text { F } & \text { G } & \text { L } & \text { V } & \text { D } & \text { Arg } \\ \text { D } & \text { P } & \text { W } & \text { G } & \text { F } & \text { G } & \text { L } & \text { V } & \text { D } & \text { Arg } \\ \text { D } & \text { P } & \text { W } & \text { G } & \text { F } & \text { G } & \text { L } & \text { V } & \text { D } & \text { Arg } \\ \text { D } & \text { P } & \text { W } & \text { G } & \text { F } & \text { G } & \text { L } & \text { V } & \text { D } & \text { Arg } \\ \text { D } & \text { P } & \text { W } & \text { G } & \text { F } & \text { G } & \text { L } & \text { V } & \text { D } & \text { Arg } \\ \text { D } & \text { P } & \text { W } & \text { G } & \text { F } & \text { G } & \text { L } & \text { V } & \text { D } & \text { Arg } \\ \text { D } & \text { P } & \text { W } & \text { G } & \text { F } & \text { G } & \text { L } & \text { V } & \text { D } & \text { Arg }\end{array}$

*According to isoforms produced 


\section{Methods \\ Bacterial strains}

Cyanobacterial strains were grown at the University of Helsinki and Norwegian Institute of Water Research (NIVA) under continuous white light at a photon irradiance of $7 \mu \mathrm{mol} \mathrm{m}^{-2} \mathrm{~s}^{-1}$ in $\mathrm{Z} 8$ medium [33].

\section{Mass spectrometry}

Microcystins were extracted from lyophilized biomass collected on glass fiber filters with $50 \% \mathrm{MeOH}$ as extraction agent. A detailed description of the method can be found in Rohrlack et al. [34].

For the identification of microcystins liquid chromatography with mass spectrometric detection (LC-MS/MS) was used. The instrumental setup included a Waters Acquity UPLC System equipped with a Waters Atlantis C18 column $(2.1 \times 150 \mathrm{~mm}, 5 \mu \mathrm{m}$ particle size $)$ and directly coupled to a Waters Quattro Premier XE tandem quadrupole MS/MS detector. The UPLC system was set to deliver a linear gradient from $20 \%$ to $60 \%$ acetonitrile in water, both containing $0.1 \%$ acetic acid, within 8 minutes at a flow rate of $0.25 \mathrm{~mL} \mathrm{~min}^{-1}$. The column and auto sampler temperatures were 20 and $4{ }^{\circ} \mathrm{C}$, respectively. At all times, the MS/MS detector was run in positive electrospray mode (ESI+). Other general settings included a source temperature of $120^{\circ} \mathrm{C}$, a desolvation temperature of $350^{\circ} \mathrm{C}$, a drying gas flow rate of $800 \mathrm{~L} \mathrm{hour}^{-1}$, a gas flow at the cone of $50 \mathrm{~L} \mathrm{hour}^{-1}$, and standard voltages and energies suggested by the manufacturer for the ESI+ mode.

To screen extracts for microcystins, the detector was run in total scanning mode for the mass range from 500 to 1100 Da over the entire UPLC gradient. At this stage, the cone voltage was $60 \mathrm{~V}$ and the time for one scan 2 seconds. Afterwards, all mass signals, that represented compounds with a molecular mass within the range of 500-1100 Da, were analyzed in fragmentation experiments. To this end, the detector was run in daughter ion scanning mode and the cone voltage and collision cell settings were optimized to obtain as many fragments of the respective compound as possible. In all cases, argon served as collision gas. Microcystins were identified by their typical fragmentation patterns including a number of immonium ions of amino acids, the characteristic Adda side chain fragment (135 Da), and a number of ring fragments. Identification was further supported by comparing fragmentation patterns with those of Microcystin LR, RR and YR standards that have been purchased from Sigma-Aldrich and by using the fragmentation simulation software HighChemMass Frontier (version 3). The precise positions of demethylations in microcystin molecules were not determined.

\section{DNA extraction, PCR amplification and sequencing}

For microcystin-producing Anabaena strains supplied by the University of Helsinki strain collection, DNA was extracted from dried cell matter with Qiagen DNeasy Plant Mini Kit (QIAGEN GmbH, Hilden, Germany). Strains from NIVA were lysed according to Chromczynski and Rymaszewski [35] and PCR performed directly on the lysate.

PCR was performed with DynaZyme II DNA polymerase (Finnzymes, Espoo, Finland) and BD Advantage ${ }^{\mathrm{TM}} 2$ polymerase (BD Biosciences, Palo Alto, CA, USA). Primers used for amplification of adenylation domains from the $m c y A B C$ operon are listed in Table 8 and their relative positions in the $m c y A B C$ operon are shown in Figure 1. Genus-specific primers for Microcystis and Anabaena were designed based on the publicly available mcy gene sequences of Microcystis aeruginosa PCC 7806 (AF183408) and UV027 (AF458094) and Anabaena strain 90 (AJ536156). Primers used for amplifying the $m c y B$ segment from Microcystis strains were placed as far as possible apart from the region involved in the recombination event between the A domain-encoding segments of $m c y B$ and $m c y C[13,15]$. The $m c y B$ regions flanking the recombination site are highly similar in all Microcystis strains (Additional file 1, Figure S1). The PCR products were purified using E.Z.N.A Gel Extraction Kit (Omega Biotek) and Montage $^{\mathrm{TM}}$ PCR Centrifugal Filter Devices (Millipore, Billerica, MA, USA). The purified PCR products were sequenced with both external and internal primers (Table $8)$. Sequencing was conducted under BigDye ${ }^{\mathrm{TM}}$ terminator cycling conditions, and sequencing reactions were purified using ethanol precipitation and separated on an Applied Biosystems 3730xl DNA Analyzer. Chromatograms were examined with the program CHROMAS 2.2 (Technelysium Pty Ltd.), while editing and contig assembly were performed with BIOEDIT sequence alignment editor. All sequences have been submitted to GenBank under accession numbers EU009866-EU009922 (Table 1). Several sequences (for Microcystis strains PCC 7806, K-139, UV027, NIES102 and Anabaena strain 90) were retrived from GenBank together with A domain sequences from Planktothrix spp. generated by Kurmayer and co-workers $[11,14]$ (Table 1).

\section{Sequence alignments and phylogenetic analyses}

Amino acid sequences of A domains from all genera were aligned using ClustalW [36]. The best evolution model based on the sequence alignment was determined using ProtTest [37]. The sequences were used to infer the phylogeny in a Bayesian framework applying the program MrBayes v3.1 [38]. Analysis with the following parameters was performed: JTT model, gamma distribution, running 2 million generations and sampling trees every 100 generation, burn-in 3000 trees. The maximum likelihood (ML) 
Table 7: Likelihood ratio tests of positive selection

\begin{tabular}{|c|c|c|c|c|c|c|c|}
\hline Genus & Region analyzed & Model & $\ln L$ & Estimates of parameters & $\omega \S$ & Positively selected sites\# & LRT \\
\hline \multirow[t]{2}{*}{ Anabaena } & mсуBI & M7 (beta) & -2249.981 & $p=0.005, q=0.01858$ & & Not allowed & $40.966 * * *$ \\
\hline & & M8 (beta and $\omega$ ) & -2229.498 & $\begin{array}{l}P_{0}=0.997, p=0.005, q= \\
0.021 \\
P_{1}=0.003, \omega=94.065\end{array}$ & 0.492 & $\begin{array}{l}\text { 243W, } \omega=3.717^{*} \\
\text { 278C, } \omega=3.935^{* *} \\
\text { 4I 4L, } \omega=4.053^{* * *}\end{array}$ & \\
\hline \multirow[t]{2}{*}{ Anabaena } & mcyC & M7 (beta) & -1695.094 & $p=0.005, q=0.0471$ & & Not allowed & $20.476 * * *$ \\
\hline & & M8 (beta and $\omega$ ) & -1684.856 & $\begin{array}{l}P_{0}=0.945, P=0.005, q= \\
2.205 \\
P_{1}=0.055, \omega=6.562\end{array}$ & 0.362 & $\begin{array}{l}\text { I25N, } \omega=6.994^{*} \\
\mid \mathbf{4 8 D}, \omega=8.098^{* * *} \\
\text { I5 I } \mathbf{Q}, \omega=7.518^{* *} \\
\mathbf{2 0 2 I}, \omega=6.992^{*} \\
\mathbf{2 0 3 T}, \omega=7.240^{* *} \\
\mathbf{2 0 5 Q}, \omega=7.240^{* * *} \\
\mathbf{2 2 3 G}, \omega=7.177^{* *} \\
\mathbf{2 7 8 S}, \omega=7.176^{* *}\end{array}$ & \\
\hline \multirow[t]{2}{*}{ Microcystis } & mcyB I & M7 (beta) & -2321.128 & $p=0.005, q=0.016$ & & Not allowed & $6.729 * *$ \\
\hline & & M8 (beta and $\omega$ ) & -2318.527 & $\begin{array}{l}P_{0}=0.942, p=0.110, q= \\
0.773 \\
P_{1}=0.058, \omega=2.584\end{array}$ & 0.356 & $\begin{array}{l}\text { 350T, } \omega=2.879^{* * *} \\
\text { 352I, } \omega=2.792^{* * *} \\
\text { 389Q, } \omega=2.727^{*} \\
\text { 404Q, } \omega=2.744^{*} \\
\text { 420E, } \omega=2.684^{*}\end{array}$ & \\
\hline \multirow[t]{2}{*}{ Microcystis } & mcyC & M7 (beta) & -2674.333 & $p=0.012, q=0.0416$ & & Not allowed & $16.516 * * *$ \\
\hline & & M8 (beta and $\omega$ ) & -2666.075 & $\begin{array}{l}P_{0}=0.976, P=0.015, q= \\
0.0811 \\
P_{1}=0.024, \omega=4.939\end{array}$ & 0.280 & $\begin{array}{l}\text { I 58Q, } \omega=3.47 \mid * * * \\
\text { 205R, } \omega=3.472^{* * *} \\
\text { 300A, } \omega=3.279^{*} \\
\text { 349R, } \omega=3.48 I^{* * *} \\
\text { 438L, } \omega=3.473^{* * *}\end{array}$ & \\
\hline \multirow[t]{2}{*}{ Planktothrix } & mсуBI & M7 (beta) & -2030.973 & $p=0.005, q=0.021$ & & Not allowed & $7.93 * * *$ \\
\hline & & M8 (beta and $\omega$ ) & -2027.008 & $\begin{array}{l}P_{0}=0.896, p=0.005, q= \\
I .883 \\
P_{1}=0.104, \omega=2.134\end{array}$ & 0.231 & $\begin{array}{l}\text { 259N, } \omega=3.074^{* * *} \\
\text { 262P, } \omega=3.187^{* * *} \\
\text { 278F, } \omega=3.005^{* * *} \\
\text { 347A, } \omega=3.000^{*}\end{array}$ & \\
\hline \multirow[t]{3}{*}{ Planktothrix } & mcyC & M7 (beta) & -1595.526 & $p=50.84, q=99.000$ & & Not allowed & 0.002 \\
\hline & & M8 (beta and $\omega$ ) & -1595.525 & $\begin{array}{l}P_{0}=1.000, p=50.442, q= \\
99.00\end{array}$ & 0.196 & & \\
\hline & & & & $P_{1}=0.000, \omega=0.539$ & & & \\
\hline
\end{tabular}

$\S$ calculated using estimates of parameters of best fitting model

\# numbering of amino acid residues according to GrsA (swissprot: P0C06I)

$* 90 \%$ confidence interval level

** $95 \%$ confidence interval level

*** $99 \%$ confidence interval level

tree was estimated using PhyML [39] under the JTT model, gamma distribution and with parameter values indicated by ProtTest. The Neighbor joining (NJ) tree was obtained under the JTT model and gamma distribution using MEGA version 3 [40]. Bootstrap confidence limits were obtained by 1000 replicates in both ML and NJ analysis. DnaSP version 3.51 [41] was used to estimate mutation rates, based on the number of segregating sites, using the Watterson's estimator of $\Theta[42]$ and the average nucleotide diversity $(\pi)[43]$.

\section{Recombination analyses and nucleotide substitution statistics}

Recombination was investigated by split decomposition analysis using SplitsTree version 4.8 [44] with default settings (uncorrected $P$ method) and 1000 bootstrap replicates together with Phi test for recombination [45]. In addition, the following statistical tests for detecting recombination were used: GENECONV [46], RDP, and MaxChi [47] analyses in the RDP version 2 b08 program package [48]. For detecting recent and older recombination events using GENECONV G-scale values 0 and 1 were used, respectively. Recombination was also detected by visual analysis of informative sites (variable sites where each variant occurs in at least two sequences) as described by Rudi et al. [24].

The recombination rate, $\rho=2 N r$ ( $N$ is the effective population size and $r$ is the recombination rate per nucleotide site per generation) was estimated for each data set using the composite likelihood method proposed by Hudson [49] and extended to allow for finite-site mutation models [50]. The method is based on combining the coalescent likelihoods of all pairwise comparisons of segregating sites. The hypothesis of no recombination was tested using the likelihood permutation test (LPT) as in McVean 


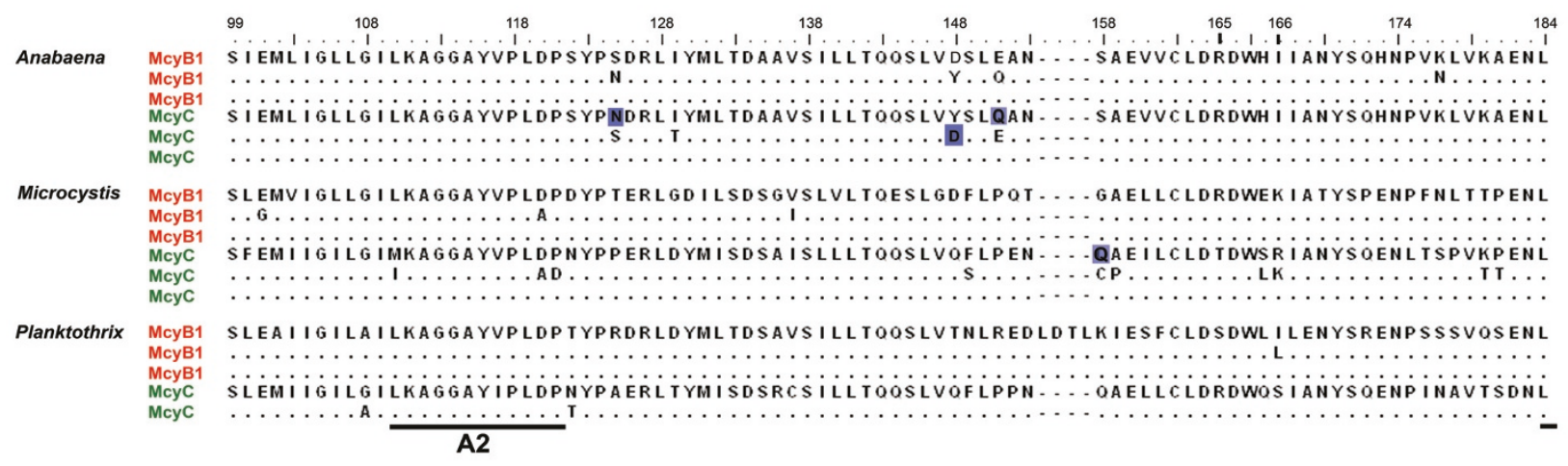

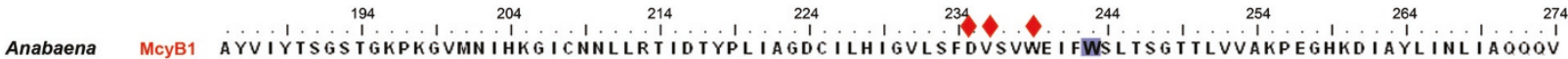

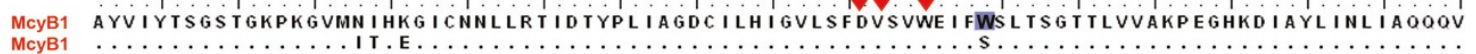
McyB1

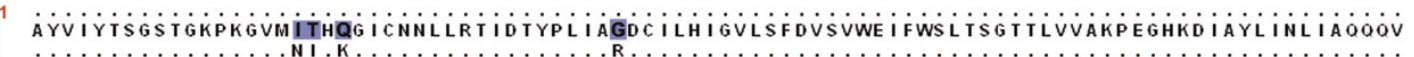
Mcyc

Microcystis

AYVIYTSGSTGKPKGVMNIHRGICNTLKYIIGHYNITSEDRILOIISLSFDGSVWEIFSSLISGASLVVAKPDGYKDIDYLIDLIVOEOV

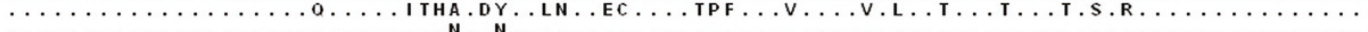

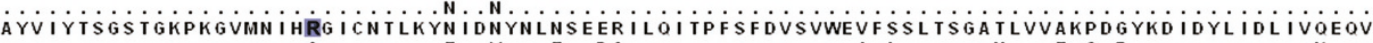

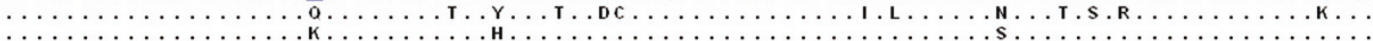

Planktothrix AYLIYTSGSTGKPKGVMNLHOG ICNN ILRTKDSYPTINRDRLLOISSLAFDASVLD IFWSLSSGMALI IPKPEGTKDLAYLIOLMIEKKV

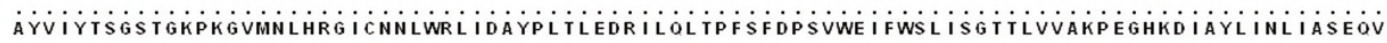
A3

A4

Anabaena

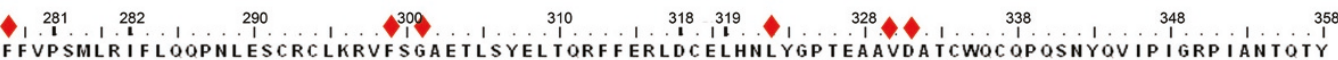
TOVFFVPSMLR IF LOOPNLESCRCLKRVF GAETLSYELTORFFERLDCELHNLYGPTEAAVDA TCWOCOPOSNYOVIP IGRP IANTOTY TOACFVPSMLRIFLOQPNLESCRYLRVFSGAETLSYELTORFFERLDCELHNLYGPTETAVDATCWOCOPDSNCRIIPIGRPIANTOTY

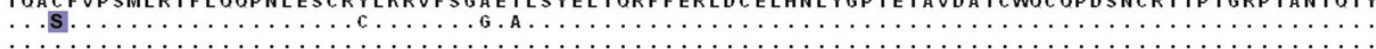

Microcystis TYF TCVPS ILRVF LOHPKSKYCHCLKRV IVGGEALSYELNORFF QQLNCELYNAYGP TEVAVETT IWCCOP . NSO. IS I GTPLANAOVY

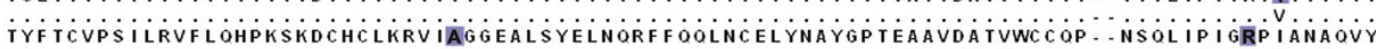

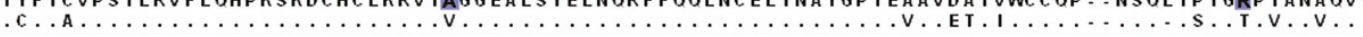
. SOVFFVPSLLRLLLOQPNLENCRYLKRVFCGGEALSSELMOQF FHFNCELHNLYGPTETSVDATCWOCPPRTDDPAIAIGRPIANTOIY

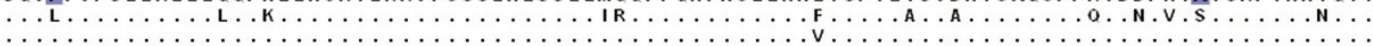

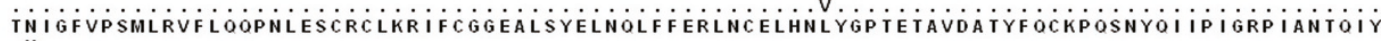

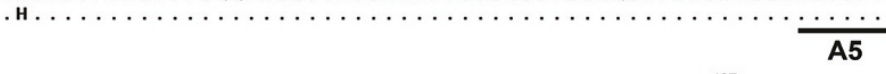

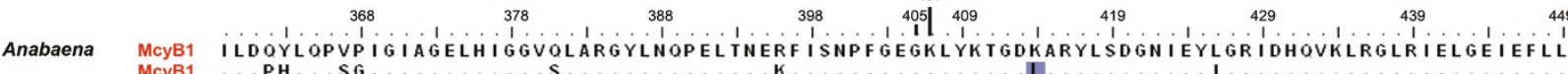

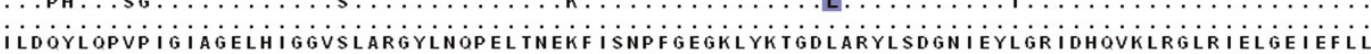

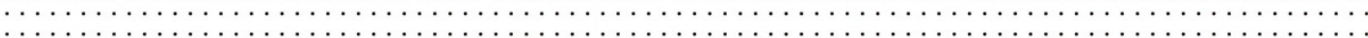
ILDSYLOPVP IGVAGELH IGGMGLARGYLNQPELTAEKFIPHPFAQGKLYKTGDLARYLPDGNIEYLGRIDNOVKLRGLRIELGEIOTVL

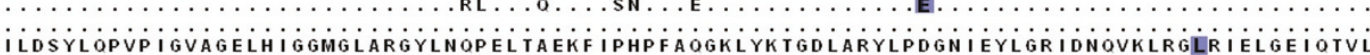
ILDSYLOPVPIGVAGELHIGGMGLARGYLNOPELTAEKF IPHPFAOGKLYKTGDLARYLPDGNIEYLGRIDNOVKLRGLRIELGEIOTVL ILDRHLOPVPVGIVGELHIGGIOLARGYLNOLELTAEKFIPNPFAGGKLYKTGDLVRYLADGNIEYLGRIDNOVKLRGLRIELGEIOTIL

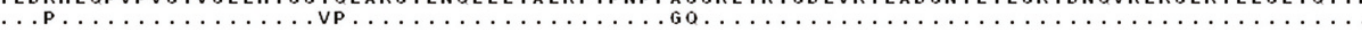

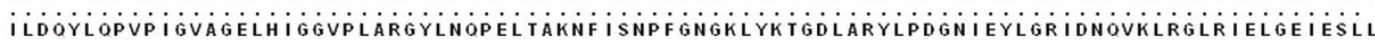
$\frac{A 6}{A 7} \cdot \frac{1}{A 8}$

Figure 7

Alignment of adenylation domain sequences of McyB I and McyC in Anabaena, Microcystis and Planktothrix strains. Identical amino acid residues within genus sequences are indicated by $\bullet$. Positions of the conserved motifs [2] are shown and binding pocket residues [32] are indicated by red diamonds. Amino acid residues undergoing positive selection are shown in dark blue boxes. Numbering of amino acid residues according to GrsA (swissprot: P0C06I). 
Table 8: Primers used.

\begin{tabular}{|c|c|c|}
\hline Primer & Sequence & Annealing temp $\left(\mathbf{C}^{\circ}\right)$ \\
\hline Microcystis-mcyB-F (PCR and sequencing) & 5'-CCCAAGAGCAACATCAGTTATTAGT-3' & 58 \\
\hline Microcystis-mcyB-R (PCR and sequencing) & 5'-TTCCTGTCTATCTTGCCATTGTTA-3' & 57 \\
\hline Microcystis-mcyB-F2 (Sequencing) & 5'-AACGACTCCTGAGAATTTAGCCTAT-3' & 60 \\
\hline Microcystis-mcyB-R2 (Sequencing) & 5'-GTCAATTCAGGTTGGTTGAGGT-3' & 60 \\
\hline Microcystis-mcyC-F (PCR and sequencing)* & 5'-CAAGAAAAAGGCGTAACTTCAGA-3' & 55 \\
\hline Microcystis-mcyC-R (PCR and sequencing)* & 5'-AAGGTATCTTCCCGCATAATC-3' & 55 \\
\hline Anabaena-mcyB-F (PCR and sequencing) & 5'-TGATTTGAAAAGAAAGACCCAAT-3' & 56 \\
\hline Anabaena-mcyB-R (PCR and sequencing) & 5'-ATACCCAAACAAGAGTTGCTCAT-3' & 59 \\
\hline Anabaena-mcyB-F2 (Sequencing) & 5'-ACTTATCCGCTTATCGCAGGT-3' & 56 \\
\hline Anabaena-mcyB-R2 (Sequencing) & 5'-CCCAATATGTAATTCTCCAGCA-3' & 56 \\
\hline Anabaena-mcyC-F (PCR and sequencing) & 5'-CTCAATTCTGCTACTGTTGGTTTT-3' & 57 \\
\hline Anabaena-mcyC-R (PCR and sequencing) & 5'-CTTACCCACTAAAACCTCGAACT-3' & 54 \\
\hline Anabaena-mcyC-F2 (Sequencing) & 5'-AGGTAAGCCAAAGGGAGTGAT-3' & 57 \\
\hline Anabaena-mcyC-R2 (Sequencing) & 5'-САССТССАATATGTAATTСТССА-3' & 57 \\
\hline
\end{tabular}

Primers Microcystis-mcyC-F and Microcystis-mcyC-R were used in [13]

et al. [50] and the permutation tests which detect a decrease in $r^{2}$ and $\left|D^{\prime}\right|$, measures of linkage disequilibrium, with an increase in the physical distance. Both the composite likelihood analysis and the three permutation tests were carried out using the LDhat package [50].

We used CODEML from the PAML v3.15 package [51] to test for the presence of codon sites affected by positive selection and to identify those sites under selection. A likelihood ratio test (LRT) for positive selection [52,53] compares two codon substitution models, one of which accounts for positive selection and the other which does not. The gene is inferred to be under positive selection if (1) ML estimates suggests that there are codon(s) under positive selection (with $\omega=\mathrm{d}_{\mathrm{n}} / \mathrm{d}_{\mathrm{s}}>1$ ) and (2) the LRT is significant. Simulations by Anisimova et al. [54] showed that high levels of recombination seem to affect dramatically the accuracy of the LRT test and that recombination often mistakenly is seen as evidence of positive selection. LRTs of M0-M3 and M1-M2 are heavily affected, while LRT of M7-M8 is much less (positive selection was falsely detected in only $20 \%$ of replicates). Therefore, models M7 (beta) and M8 (beta and $\omega$ ) were considered in present study. Under the model M7 (beta), the $\omega$ ratio various according to the beta distribution and does not allow the positive selected sites $(<\omega<1)$, and thus serves as the null model by comparing with model M8 (beta and $\omega$ ). Model M8 adds an additional site class to the beta model to account for sites under positive selection $(\omega>1)$. A Bayesian approach implemented in CODEML and shown to be robust to recombination effects [54] was used to identify residues under positive selection. The average $\omega$ for A domain sequences was calculated using the parameters of the best fitting model.
Branch-site models [55] were employed to test for positive selection acting on specific branches in the phylogenetic tree. Branches of the tree were divided $a$ priori into foreground and background lineages, and a LRT was constructed by comparing a model that allows positive selection on the foreground lineages (alternative model) with a model that does not allow such positive selection (the null model).

\section{Abbreviations}

BS: bootstrap; LC-MS/MS: liquid chromatography with mass spectrometric detection; MC-LR: leucine and arginine in the positions of $\mathrm{X}$ and $\mathrm{Z}$ of microcystin; $\mathrm{MC}$ $\mathrm{RR}$ : arginine in the positions of $\mathrm{X}$ and $\mathrm{Z}$ of microcystin; MC-HtyR: homotyrosine and arginine in the positions of $\mathrm{X}$ and $\mathrm{Z}$ of microcystin; MC-YR: tyrosine and arginine in the positions of $\mathrm{X}$ and $\mathrm{Z}$ of microcystin; ML: maximum likelihood; NJ: neighbor joining; PP: Posterior Probability.

\section{Authors' contributions}

ATK designed the study, contributed to molecular studies, performed the phylogenetic, recombination, mutation and selection analysis and drafted the manuscript. DPF: Contributed to molecular studies and helped draft the manuscript. TR: performed the LC-MS/MS analysis and helped draft the manuscript. JJ: performed the LC-MS/MS analysis of certain Anabaena strains. LR: revised the manuscript. KS: participated in coordination of the study at HU and revised the manuscript. TK and KSJ participated in the design of the study, interpretation of the results and revision of the manuscript. All authors read and approved the final manuscript. 


\section{Additional material}

\section{Additional file 1}

Phylogenetic analysis of adenylation domain amino acid sequences including B-type of McyB1 sequences from Microcystis.

Click here for file

[http://www.biomedcentral.com/content/supplementary/14712148-8-256-S1.doc]

\section{Acknowledgements}

We thank Randi Skulberg for providing the N-C strains and Lyudmila Saari for her valuable help in handling the cultures at University of Helsinki. We also thank Matti Wahlsten for help with microcystin analysis. This work was in part supported by projects I57338// 40 and I59822/V40 from the Norwegian Research Council to K.S.J. and in part by the grants from the Academy of Finland to D.F. (1212943) and K.S (53305 and 214457).

\section{References}

I. Welker M, von Döhren H: Cyanobacterial peptides - nature's own combinatorial biosynthesis. FEMS Microbiology Reviews 2006, 30(4):530-563.

2. Marahiel MA, Stachelhaus T, Mootz HD: Modular Peptide Synthetases Involved in Nonribosomal Peptide Synthesis. Chem $\operatorname{Rev}$ 1997, 97(7):2651-2674

3. Fewer DP, Rouhiainen L, Jokela J, Wahlsten M, Laakso K, Wang $\mathrm{H}$, Sivonen K: Recurrent adenylation domain replacement in the microcystin synthetase gene cluster. BMC Evol Biol 2007, 7(I): 183 .

4. Lodders N, Stackebrandt E, Nubel U: Frequent genetic recombination in natural populations of the marine cyanobacterium Microcoleus chthonoplastes. Environ Microbiol 2005, 7(3):434-442.

5. Zeidner G, Bielawski JP, Shmoish M, Scanlan DJ, Sabehi G, Beja O: Potential photosynthesis gene recombination between Prochlorococcus and Synechococcus via viral intermediates. Environ Microbiol 2005, 7( I 0): I505-15 I3.

6. Christiansen G, Fastner J, Erhard M, Börner T, Dittmann E: Microcystin biosynthesis in Planktothrix: genes, evolution, and manipulation. J Bacteriol 2003, I 85(2):564-572.

7. Nishizawa T, Asayama M, Fujii K, Harada K, Shirai M: Genetic analysis of the peptide synthetase genes for a cyclic heptapeptide microcystin in Microcystis spp. I Biochem (Tokyo) 1999, I 26(3):520-529.

8. Nishizawa T, Ueda A, Asayama M, Fuji K, Harada K, Ochi K, Shirai M: Polyketide synthase gene coupled to the peptide synthetase module involved in the biosynthesis of the cyclic heptapeptide microcystin. J Biochem (Tokyo) 2000, I 27(5):779-789.

9. Rouhiainen L, Vakkilainen T, Siemer BL, Buikema W, Haselkorn R, Sivonen K: Genes coding for hepatotoxic heptapeptides (microcystins) in the cyanobacterium Anabaena strain 90. Appl Environ Microbiol 2004, 70(2):686-692.

10. Tillett D, Dittmann E, Erhard M, von Döhren H, Börner T, Neilan BA: Structural organization of microcystin biosynthesis in Microcystis aeruginosa PCC7806: an integrated peptide-polyketide synthetase system. Chem Biol 2000, 7(10):753-764.

II. Kurmayer R, Gumpenberger M: Diversity of microcystin genotypes among populations of the filamentous cyanobacteria Planktothrix rubescens and Planktothrix agardhii. Mol Ecol 2006, I 5( I 2):3849-386 I.

12. Tanabe Y, Kaya K, Watanabe MM: Evidence for recombination in the microcystin synthetase (mcy) genes of toxic cyanobacteria Microcystis spp. J Mol Evol 2004, 58(6):633-64I.

13. Tooming-Klunderud A, Mikalsen B, Kristensen K, Jakobsen KS: The mosaic structure of the mcyABC operon in Microcystis. Microbiology 2008, I 54(7): 1886-1899.

14. Kurmayer R, Christiansen G, Gumpenberger M, Fastner J: Genetic identification of microcystin ecotypes in toxic cyanobacteria of the genus Planktothrix. Microbiology 2005, I I (5): I 525-I 533.
15. Mikalsen B, Boison G, Skulberg OM, Fastner J, Davies W, Gabrielsen TM, Rudi K, Jakobsen KS: Natural variation in the microcystin synthetase operon mcyABC and impact on microcystin production in Microcystis strains. J Bacteriol 2003, I 85(9):2774-2785.

16. Dittmann E, Neilan BA, Erhard M, von Döhren H, Börner T: Insertional mutagenesis of a peptide synthetase gene that is responsible for hepatotoxin production in the cyanobacterium Microcystis aeruginosa PCC 7806. Mol Microbiol 1997, 26(4):779-787.

17. Kaneko T, Nakajima N, Okamoto S, Suzuki I, Tanabe $Y$, Tamaoki M, Nakamura $Y$, Kasai F, Watanabe A, Kawashima K, Kishida Y, Ono A, Shimizu Y, Takahashi C, Minami C, Fujishiro T, Kohara M, Katoh M, Nakazaki S, Yamada M, Tabata S, Watanabe MM: Complete genomic structure of the bloom-forming toxic cyanobacterium Microcystis aeruginosa NIES-843. DNA Res 2007, I4(6):247-256.

18. Lautru S, Challis GL: Substrate recognition by nonribosomal peptide synthetase multi-enzymes. Microbiology 2004, 150(6): 1629-1636.

19. Rounge TB, Rohrlack T, Tooming-Klunderud A, Kristensen T, Jakobsen KS: Comparison of cyanopeptolin genes in Planktothrix, Microcystis and Anabaena: evidence for independent evolution within each genus. Appl Environ Microbiol 2007, 73:7322-7330.

20. Conti E, Stachelhaus T, Marahiel MA, Brick P: Structural basis for the activation of phenylalanine in the non-ribosomal biosynthesis of gramicidin S. Embo J 1997, I6( I 4):4174-4I83.

21. Rantala A, Fewer DP, Hisbergues M, Rouhiainen L, Vaitomaa J, Börner $\mathrm{T}$, Sivonen K: Phylogenetic evidence for the early evolution of microcystin synthesis. Proc Natl Acad Sci USA 2004, IOI(2):568-573.

22. Tooming-Klunderud A, Rohrlack T, Shalchian-Tabrizi K, Kristensen T, Jakobsen KS: Structural analysis of a non-ribosomal halogenated cyclic peptide and its putative operon from Microcystis: implications for evolution of cyanopeptolins. Microbiology 2007, I 53(5): | 382-1393.

23. Papke RT, Zhaxybayeva O, Feil EJ, Sommerfeld K, Muise D, Doolittle WF: Searching for species in haloarchaea. Proc Natl Acad Sci USA 2007, 104(35): $14092-14097$

24. Rudi K, Skulberg OM, Jakobsen KS: Evolution of cyanobacteria by exchange of genetic material among phyletically related strains. J Bacteriol 1998, I 80( I3):3453-346I.

25. Zhaxybayeva O, Gogarten JP, Charlebois RL, Doolittle WF, Papke RT: Phylogenetic analyses of cyanobacterial genomes: quantification of horizontal gene transfer events. Genome Res 2006, 16(9): 1099-1108.

26. Posada D, Crandall KA: Evaluation of methods for detecting recombination from DNA sequences: computer simulations. Proc Natl Acad Sci USA 200I, 98(24): I $3757-13762$

27. Lovett ST, Hurley RL, Sutera VA Jr, Aubuchon RH, Lebedeva MA: Crossing over between regions of limited homology in Escherichia coli. RecA-dependent and RecA-independent pathways. Genetics 2002, 160(3):851-859.

28. Majewski J, Cohan FM: DNA sequence similarity requirements for interspecific recombination in Bacillus. Genetics 1999, 153(4): I525-1533.

29. Shen P, Huang HV: Homologous recombination in Escherichia coli: dependence on substrate length and homology. Genetics 1986, I I 2(3):44I-457.

30. Mes TH, Doeleman M, Lodders N, Nubel U, Stal LJ: Selection on protein-coding genes of natural cyanobacterial populations. Environ Microbiol 2006, 8(9): I534-I543.

31. Challis GL, Ravel J, Townsend CA: Predictive, structure-based model of amino acid recognition by nonribosomal peptide synthetase adenylation domains. Chem Biol 2000, 7(3):2 I I-224.

32. Stachelhaus T, Mootz HD, Marahiel MA: The specificity-conferring code of adenylation domains in nonribosomal peptide synthetases. Chem Biol 1999, 6(8):493-505.

33. Kotai J: Instructions for preparation of modified nutrient solution Z8 for algae. Norwegian Institute for Water Research, publication B-I I/69. Oslo, Blindern; 1972.

34. Rohrlack T, Christoffersen K, Hansen PE, Zhang W, Czarnecki O, Henning M, Fastner J, Erhard M, Neilan BA, Kaebernick M: Isolation, characterization, and quantitative analysis of Microviridin J, a new Microcystis metabolite toxic to Daphnia. J Chem Ecol 2003, 29(8): $1757-1770$. 
35. Chomczynski P, Rymaszewski M: Alkaline polyethylene glycolbased method for direct PCR from bacteria, eukaryotic tissue samples, and whole blood. BioTechniques 2006, 40(4):454, 456, 458.

36. Thompson J, Gibson T, Plewniak F, Jeanmougin F, Higgins D: The CLUSTAL_X windows interface: flexible strategies for multiple sequence alignment aided by quality analysis tools. Nucleic Acids Res 1997, 25:4876-4882.

37. Abascal F, Zardoya R, Posada D: ProtTest: selection of best-fit models of protein evolution. Bioinformatics 2005, 2I(9):2104-2105.

38. Ronquist F, Huelsenbeck J: MrBayes 3: Bayesian phylogenetic inference under mixed models. Bioinformatics 2003, 19:1572-1574.

39. Guindon S, Gascuel O: A simple, fast, and accurate algorithm to estimate large phylogenies by maximum likelihood. Syst Biol 2003, 52(5):696-704.

40. Kumar S, Tamura K, Nei M: MEGA3: Integrated Software for Molecular Evolutionary Genetics Analysis and Sequence Alignment. Briefings in Bioinformatics 2004, 5:150-163.

41. Rozas J, Rozas R: DnaSP version 3: an integrated program for molecular population genetics and molecular evolution analysis. Bioinformatics 1999, I 5(2): 174-175.

42. Watterson GA: On the number of segregating sites in genetical models without recombination. Theor Popul Biol 1975, 7(2):256-276.

43. Tajima F: Evolutionary relationship of DNA sequences in finite populations. Genetics 1983, I05(2):437-460.

44. Huson DH, Bryant D: Application of phylogenetic networks in evolutionary studies. Mol Biol Evol 2006, 23(2):254-267.

45. Bruen TC, Philippe H, Bryant D: A simple and robust statistica test for detecting the presence of recombination. Genetics 2006, I72(4):2665-268I.

46. Padidam M, Sawyer S, Fauquet CM: Possible emergence of new geminiviruses by frequent recombination. Virology 1999, 265(2):2। 8-225.

47. Posada D, Crandall KA, Holmes EC: Recombination in evolutionary genomics. Annu Rev Genet 2002, 36:75-97.

48. Martin DP, Williamson C, Posada D: RDP2: recombination detection and analysis from sequence alignments. Bioinformatics 2005, 2 I (2):260-262.

49. Hudson RR: Two-locus sampling distributions and their application. Genetics 200I, I59(4):1805-18I7.

50. McVean GA: A genealogical interpretation of linkage disequilibrium. Genetics 2002, 162(2):987-991.

5I. Yang Z: PAML: a program package for phylogenetic analysis by maximum likelihood. Comput Appl Biosci 1997, I 3(5):555-556.

52. Nielsen R, Yang Z: Likelihood models for detecting positively selected amino acid sites and applications to the HIV-I envelope gene. Genetics 1998, I48(3):929-936.

53. Yang Z, Nielsen R, Goldman N, Pedersen AM: Codon-substitution models for heterogeneous selection pressure at amino acid sites. Genetics 2000, I 55(I):431-449.

54. Anisimova M, Nielsen R, Yang Z: Effect of recombination on the accuracy of the likelihood method for detecting positive selection at amino acid sites. Genetics 2003, 164(3): 1229-1236.

55. Zhang J, Nielsen R, Yang Z: Evaluation of an improved branchsite likelihood method for detecting positive selection at the molecular level. Mol Biol Evol 2005, 22(I 2):2472-2479.

56. Fewer D, Tooming-Klunderud A, Jokela J, Wahlsten M, Rouhiainen $L$, Kristensen K, Rohrlack T, Jakobsen KS, Sivonen K: Natural occurrence of microcystin synthetase deletion mutants capable of producing microcystins in strains of the genus Anabaena (Cyanobacteria). Microbiology 2008, 154:1007-1014.

57. Haande S, Ballot A, Rohrlack T, Fastner J, Wiedner C, Edvardsen B: Diversity of Microcystis aeruginosa isolates (Chroococcales, Cyanobacteria) from East-African water bodies. Arch Microbiol 2007, I 88(I): 15-25.

58. Kameyama K, Sugiura N, Inamori Y, Maekawa T: Characteristics of microcystin production in the cell cycle of Microcystis viridis. Environ Toxicol 2004, I (1):20-25.

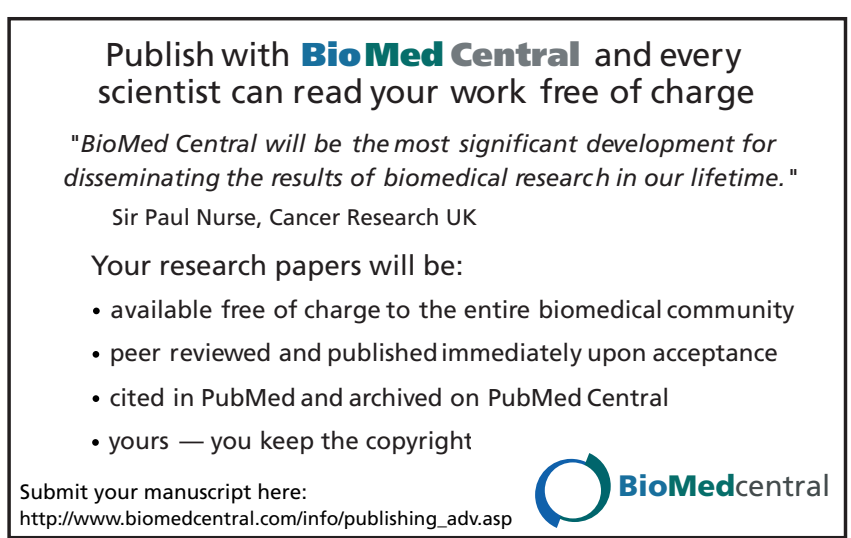

